\title{
Visualizing the Impacts of Extreme Weather Events Using 3D Visualization to Aid Pre-Event Risk Communication
}

Thomas L. Brown

Follow this and additional works at: https://researchrepository.wvu.edu/etd

\section{Recommended Citation}

Brown, Thomas L., "Visualizing the Impacts of Extreme Weather Events Using 3D Visualization to Aid PreEvent Risk Communication" (2017). Graduate Theses, Dissertations, and Problem Reports. 5268. https://researchrepository.wvu.edu/etd/5268

This Thesis is protected by copyright and/or related rights. It has been brought to you by the The Research Repository @ WVU with permission from the rights-holder(s). You are free to use this Thesis in any way that is permitted by the copyright and related rights legislation that applies to your use. For other uses you must obtain permission from the rights-holder(s) directly, unless additional rights are indicated by a Creative Commons license in the record and/ or on the work itself. This Thesis has been accepted for inclusion in WVU Graduate Theses, Dissertations, and Problem Reports collection by an authorized administrator of The Research Repository @ WVU. For more information, please contact researchrepository@mail.wvu.edu. 
Visualizing the Impacts of Extreme Weather Events using 3D visualization to aid pre-event risk communication

\title{
Thomas L. Brown
}

\author{
Thesis submitted \\ to the Eberly College of Arts and Sciences \\ at West Virginia University \\ in partial fulfillment of the requirements for the degree of \\ Master of the Arts in \\ Geography \\ Dr. Trevor Harris, Ph.D., (chair) \\ Dr. Insu Hong, Ph.D. \\ Dr. Eungul Lee, Ph.D.
}

Department of Geology and Geography

Morgantown, West Virginia

2017

Keywords: 3D modeling, Extreme weather, risk perception, GIScience, Geography

Copyright 2017 Thomas L. Brown 


\begin{abstract}
Visualizing the Impacts of Extreme Weather Events using 3D visualization
\end{abstract}

Thomas L. Brown

Weather is everywhere. Rapidly expanding capabilities in information technology present an opportunity to develop better warning products for extreme weather events. In the wake of recent extreme events from Superstorm Sandy to Hurricane Matthew, the National Oceanic and Atmospheric Administration and the National Weather Service have repeated the call for improving techniques for disseminating critical information to the general public during potential weather disasters. This research uses 3D GIS and geovisualization to improve the communication of expert risk information to the general public. 


\section{Table of Contents}

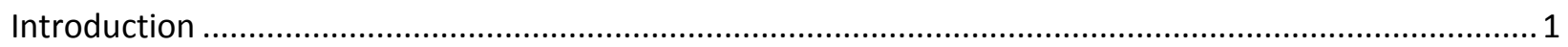

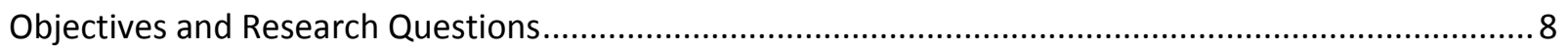

Chapter 2 - Weather, Disaster, and Information Communication ......................................................... 10

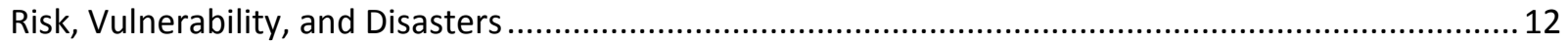

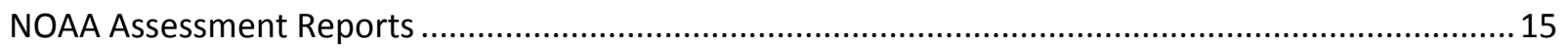

Chapter 3 - Methodology: embedding hurricane damage in a 3D GIS ................................................ 23

Chapter 4 - CityEngine, Computer Generated Architecture, and hurricane storm damage .................... 41

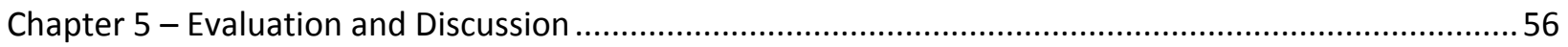

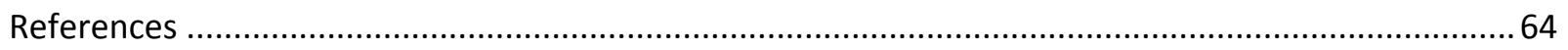

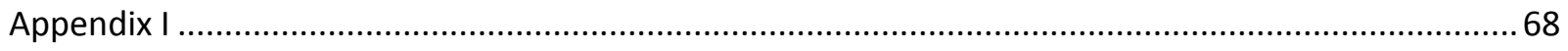

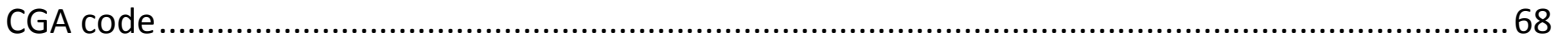

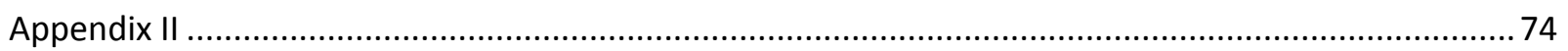

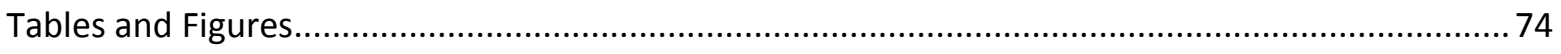

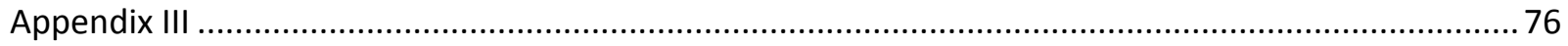

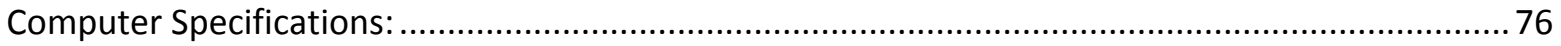


“People will gravitate towards whatever piece of information that will convince them that they don't have a hurricane problem", Dr. Rick Knabb, Director, National Hurricane Center

"A hurricane is not just a point on a map!", Dr. Rick Knabb, Operational Forecast at National Hurricane Center, Hurricane Matthew (Live Broadcast, September, 2016)

\section{Introduction}

Weather is everywhere. Communicating information to the public about weather events and their severity can help to save lives and prevent damage to property. In addition, weather events can quickly turn into extremely dangerous scenarios if conditions change, predictions are incorrect, or if the warnings go unheeded. There is seemingly no place on earth where people live that is devoid of risk from weather and related disasters. Extreme weather events can block important transportation routes, impede access to food and water, and render thousands of households and services in an area without electricity. Weather events affect where we live and conduct business. Extreme weather can change communities and the way in which they evaluate the security of the spaces and places they call home (Cutter et al. 2006). The scientific community and communication industry is challenged to not only predict, but to communicate the risks associated with extreme weather events to the public in order to reduce vulnerability, improve public response, and mitigate risk (White et al. 2010, 219). It is difficult to forecast when a routine weather event will turn into a disastrous emergency but connecting expert meteorological knowledge with emergency managers and the general public through three-dimensional (3D) modeling and geovisualization could arguably assist in better risk communication and public assessment.

Currently, information about weather hazards is largely conveyed in the form of twodimensional maps, text-based messages, or verbal announcements. Each of these forms it has been 
argued, limit the full comprehension of the potential magnitude and impact of a weather event by nonexperts (Sullivan 2013; Knabb 2015). Wireless emergency alerts from local emergency managers are limited to 90 characters and often lack the information people need to comprehend the full magnitude and severity of an event in order for them to take appropriate action (Broad et al. 2007, 651-667). Individuals are often not conversant with the official terminology and the risks associated with different warnings, watches, and advisories (Peacock, Brody and Highfield 2005, 120-135). For example, hurricane categories are defined by one minute average wind speeds, yet individuals do not typically associate wind speeds with related risks to life and property (Saffir-Simpson 2013). In addition, hurricanes carry risks such as inland storm surge flooding, tornadoes, and lightning strikes. The general public does not readily absorb weather information in numerical or measured form or know how to equate this information to real world events, especially in the case of out of the ordinary extreme weather events (White et al. 2010, 219). Information about weather that is conveyed by probability, such as 50 percent chance of rain, or rates such as 40 mile-per-hour wind speeds, present challenges in translating that information meaningfully to a public audience. These challenges have posed questions as to what is the best way to inform the general public and bridge the gap between expert level event knowledge and the public's potential lived experience? The different perceptions of risk from weather events between experts and the general public arguably inhibits the ability of the general public to make informed decisions that are outside the realms of their everyday experiences and to take appropriate action to protect lives and property.

As Dr. Rick Knabb, director of the National Hurricane Center (NHC) poignantly notes, "people will gravitate towards whatever piece of information that will convince them that they don't have a hurricane problem" because the circumstances of evacuation and preparation are difficult, inconvenient, and uncomfortable (Knabb 2015). According to Nicholson-Cole and Sheppard (2005; 2005), the current ways for communicating extreme weather messages to the public need to be clearer 
and more effective to be used in the most effective manner. Furthermore they note that the messages should be pertinent to the differing needs and circumstances of user groups. People in flood prone areas need to understand the nature of the flood risk just as those in the path of high wind speeds should understand associated high wind risks. Uncertainty in weather forecasts can decrease the effectiveness of risk communication. Hurricane Sandy and New York City represents an extreme case where many individuals did not evacuate or prepare in any noteworthy way because the previous years' hurricanes did not make significant landfall in the region. This inaction resulted in a state of unpreparedness among many of the individuals who stayed in the path of the storm as it approached. The public interpretation of expert information can confuse and even render populations complacent because they do not understand what the experts are trying to communicate or fail to truly comprehend the risks associated with such warnings.

More recently during Hurricane Matthew, National Weather Service (NWS) personnel and weather forecasters struggled to communicate during Hurricane Matthew that "a hurricane is not just a point on a map" (Dr. Rick Knabb, Hurricane Matthew Forecast recording, NHC). One of the main products provided by the NHC is storm track probability maps. These maps show the probable path of a storm and the central location of the eye - the area of extreme low pressure in the center of a hurricane. Winds are typically highest near the eyewall and its location often becomes the focus of forecasters and emergency managers (Franklin et al. 2000). This method of information communication can make appropriate risk awareness more difficult for the general public because people become fixated on the specific center or landfall point of the storm instead of the broad impacts that the storm will have across the region (See Figure 1.1). The struggle to communicate the potential impact and the importance of preparation and evacuation is long-lived in the emergency management and disaster risk preparedness communities (Demuth et al. 2009, Sullivan 2013). Products from both broadcast media and official 
government organizations can be misleading for the general public and result in failure to adequately prepare and/or evacuate storm impact areas (Figure 1.2).

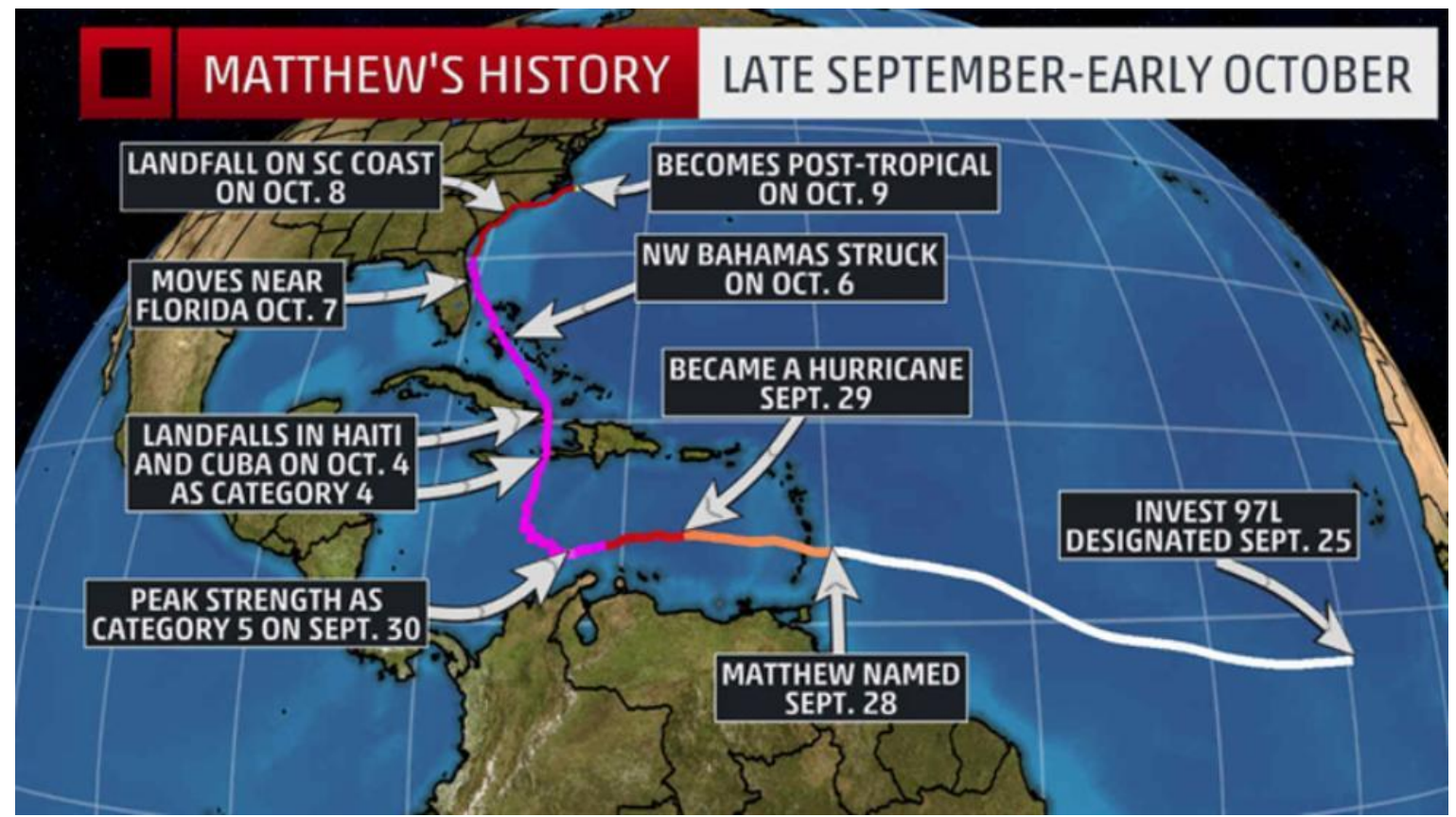

Figure 1.1 - Tracking the Eye of the Storm Source: The Weather Channel, Hurricane Matthew Track, Oct.

9, 2016) 


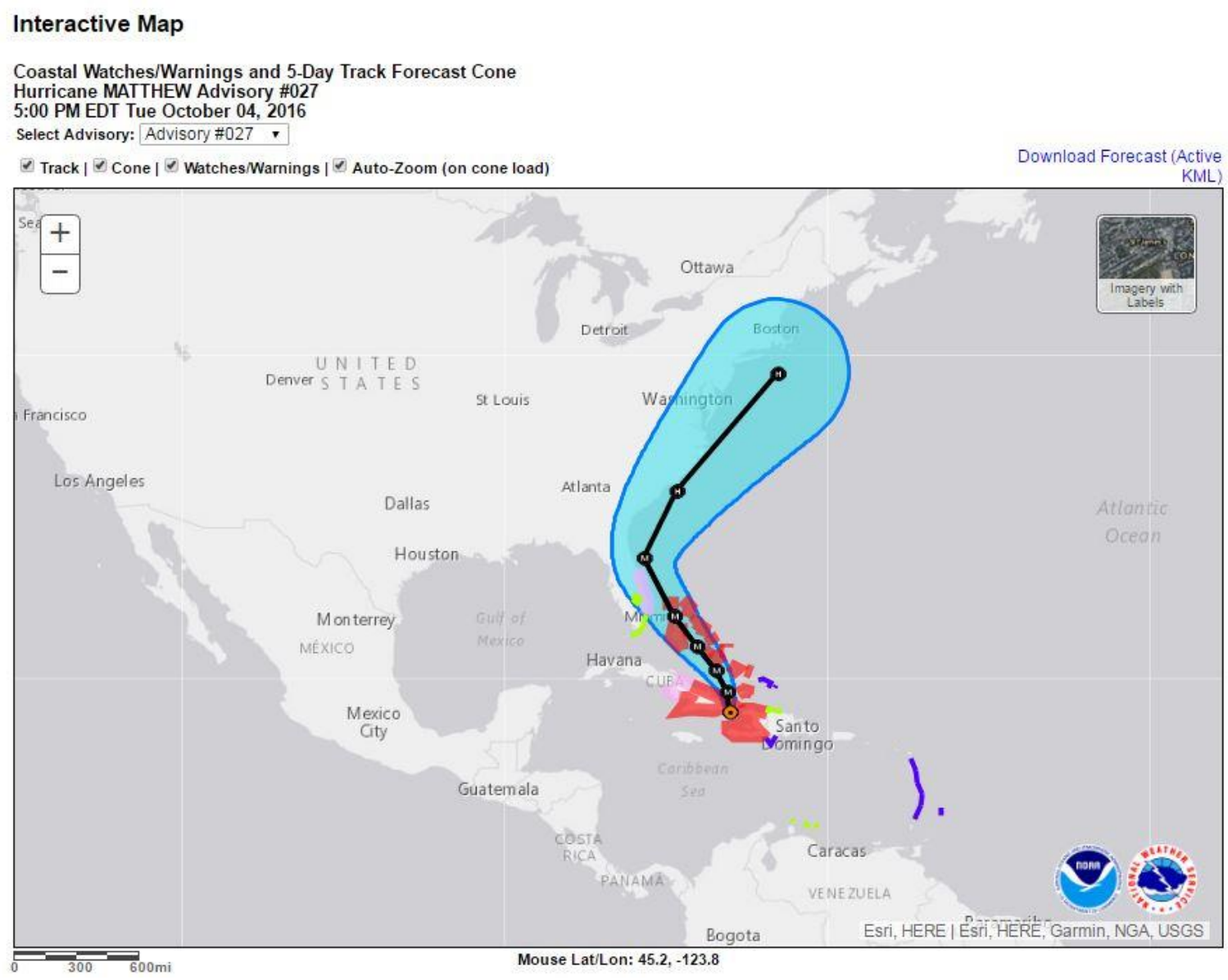

Figure 1.2 - Hurricane Matthew, Tracking the Cone of Probability Source: National Hurricane Center, Hurricane Matthew Cone of Probability, Oct. 4, 2016

The Saffir-Simpson Hurricane Wind Scale is a series of five categories that represent a range of 1 minute average sustained wind speed which is used to determine the relative strength of a hurricane. Hurricanes are categorized numerically using the integer values 1 through 5 by measuring the sustained wind speed at "10m over unobstructed exposure" (Saffir-Simpson 2012, 1). The scale is used to provide examples of the type of impacts, including damage to structures, which occur during hurricanes. It should be noted that "the scale does not address the potential for other hurricane-related impacts, such as storm surge, rainfall-induced floods, and tornadoes." (ibid. 2012, 1). 
The NOAA webpage (http://www.nhc.noaa.gov/aboutsshws.php) that describes the SaffirSimpson Hurricane Wind Scale has an animation that shows the destruction of a home and surrounding trees as wind speeds increase from categories 1 through 5 (Saffir-Simpson 2013). This visual information product allows people to see what the predicted conditions will do to a single standing home, but has little impact on their perception of that risk to an entire community. Nicholson-Cole (2005) finds that changes in behavior and the course of subsequent action or inaction depend on making these messages personally and locally relevant. Multiple NOAA service assessments have recognized the need for better communicating the risks involved with approaching weather events that respond to changes in the spatial and temporal dimensions of the event (Jannuzzi et al. 2010; Sullivan, 2013; Vallee et al. 2013). Products such as the NOAA hurricane animation and the work of Nicholson-Cole (2005) represent developments in scientific communication that draw upon the communicative power of visual information for the benefit of the many stakeholders involved. This research intends to address the task of making 3D visual information products reproducible, locally relevant, and representative of the possible damage from hurricane events. The aim of this research is to deepen the impact specific message of the Saffir-Simpson Hurricane Wind Scale by creating a prototype visual and intuitive 3D geovisualization of Saffir-Simpson Hurricane Wind Scale damage categories.

Landscape visualization presents a significant challenge for weather communication products because of the variation in experience from one individual to the next. The work of Sheppard (2005) on future scenarios under climate change investigates human response to landscape visualizations in order to better inform the population about environmental change. He notes that "if visualization succeeds at...reducing ignorance or denial, then this should be beneficial, particularly if it is more effective than other forms of communication," (ibid. 2005, 645). Sheppard suggests that effective landscape visualization should reinforce the conceptual understandings of different phenomena in order to 
improve public understanding of it: making "the abstract tangible, collapsing long time scales into short periods, and easily switching between different scales" (ibid. 2005, 645).

Flowing from these challenges, the task of hurricane damage visualization and information communication is to bridge a gap between groups with often drastically different levels of knowledge. One group, the expert, understands the implications of the abstract representations of storm intensity and is able to translate storm metrics into a probable scenario of what will likely occur on the ground (Figure 1.2). Other groups, such as the general public and laypersons may understand far less about the specific impacts of precise wind speeds, storm sizes and precipitation rates, and could benefit greatly from a communication product designed to translate expert information, and yet lend itself to intuitive understanding by the general public (as in Figure 1.1). In this sense and as discussed below, hurricane damage visualization is a boundary object, whereby experts can embed real storm metrics and damage predictions into an intuitive 3D visualization product designed for use by the general public.

Scientific descriptions of hurricanes and a system for visualization of the effects of specific hurricane attributes represents a potential process of information dissemination with far reaching implications for emergency management and disaster preparedness. Boundary objects, as defined by Star and Griesemer in their 1989 article on institutional ecology, are "those scientific objects which both inhabit several intersecting worlds and satisfy the informational requirements of both of them" (Star and Griesemer 1989, 393). The research proposed here seeks to make available tangible visual representations of damage from weather events through the use of 3D models and visualization. These visualizations can be utilized to show the general public the issues and potential risks associated with an approaching weather event and aid in enhancing awareness and decision-making before the event arrives. In particular, and as discussed later, this research involves a 3D visualization whereby individuals can engage with a boundary object to decrease the knowledge differential between weather 
experts, emergency managers, and the general public alike (ibid. 387-420). Thus, using a 3D model of a post-disaster area might be valuable to emergency managers and public safety personnel as well as to the general public by providing powerful and intuitive visualizations of the potential impact of a weather event on their home and neighborhood. Arguably, those who are responsible for getting the message out can do so more effectively, and those individuals receiving the message will be more receptive because the information about potential impacts and damage could be more intuitively represented within the announcement.

\section{Objectives and Research Questions}

The goal of this research then is to develop and visualize 3D GIS models of post-weather event damage within visualizations as a means of communicating the potential risks associated with a hurricane event. The following questions have been addressed in order to investigate this goal:

1. What is the importance of extreme weather events in everyday life and what are the varied public responses to such events?

2. How are the impacts and severity of weather events, and especially hurricanes, reported by experts?

3. What are the main damage characteristics arising from Category 1 to 5 hurricanes?

4. How might procedural mass production 3D representations of potential hurricane damage be created and then utilized to display the visual impacts of Category 1-5 hurricanes on the built environment?

5. Is it possible to display these products to the public in a way that positively influences public behavior in response to the potential event?

6. How useful are these 3D representations in communicating information to the public about potential hurricane impacts? 
This research is challenged with taking expert information about hurricane risks and transforming it to a more comprehensible representation capable of meaningfully communicating that information to members of the general public. This transformation takes text descriptions of hurricane categories and breaks them down into component forms that can be represented in a 3D model. As explored in the following chapter, rapid and widespread information dissemination is the most frequently mentioned area of improvement in NOAA/NWS service assessments in the past 10 years (Sullivan 2013). The fact remains, however, that emergency weather information dissemination stands at a critical nexus of science and public awareness as to what are the best ways to inform a group of people to take action to protect themselves from the potential impacts of severe weather? 


\section{Chapter 2 - Weather, Disaster, and Information Communication}

This chapter outlines current forecast practices employed by the National Oceanic and Atmospheric Administration (NOAA) along with broadcast media efforts to disseminate relevant information to the general public. The chapter details a variety of forecast graphics and text-based information products used to measure and communicate extreme weather events. This chapter also highlights multiple research efforts coordinated by the National Weather Service (NWS) to research the effectiveness of forecast products and information dissemination strategies (Demuth et al. 2009, Gladwin et al. 2009, Demuth et al. 2012, Sullivan 2013). There has been a lack of research publications that include a robust evaluation or survey of the general public and that investigates the effectiveness of forecast dissemination, impact, and uncertainty communication. However, there have been multiple efforts to gather information from experienced broadcast media forecasters and members of emergency management communities through NOAA NWS Service Assessments. These official assessments provide critical insight into the underpinnings of operational emergency weather forecasts. This critical insight helps to inform the subsequent development of a 3D Hurricane Damage model aimed at enhancing pre-event risk awareness for the general public.

Weather happens every day as the earth absorbs heat from the sun and the atmosphere redistributes it. Weather disasters happen when multiple human and physical phenomena interact in a certain location and create profound impacts on human and economic systems. Weather disasters can severely alter the human built environment and community life and it would seem imperative to find the best ways to prepare communities and reduce the debilitating impacts of extreme weather events. Regular communication of forecast uncertainty in broadcasted weather reports can help individuals understand the dynamic nature of extreme weather events as the storm approaches, and hopefully inform them of the best ways to take meaningful action. 
Forecast and uncertainty communication are critical to help prevent extreme weather events from progressing into disasters, but providing context to the potential impacts of extreme weather for audiences can prove to be difficult given current text-based and graphical communication methods. Packaging information communication products for consumption by the general public is not the usual focus of products from NOAA/NWS/NH. Instead, these agencies act as expert support teams for local emergency managers, private weather forecasters, and broadcast news media (Morss et Al. 2008, Rouleau et al. 2016). Many critical emergency services depend on support from NOAA/NWS employees but the message is for the general public, since they are the ones who eventually receive the instructions on how to respond to extreme events.

"Here's my take: There's a risk that we're going to see some severe weather tomorrow. And if we do see it, it's most likely going to be during the afternoon and early evening hours. If you're making plans for [a holiday], you need to be watching the weather closely from noon on. Now, that's an expression of uncertainty, because I don't know what time's it's going to occur. In fact, I don't even know if it is going to occur, but if it is, it's going to be sometime between these parameters. For a person making plans, that's probably more useful than slight, moderate, or high. And it's probably more useful than a probability too, because I'm expressing my confidence level right there." [Participant \#3] (Demuth et al. 2009).

This full quote from a broadcast meteorologist gives an idea of the nuanced nature of uncertainty and impact communication. In the case of Participant \#3, an attempt is being made to draw a distinction between predicted conditions and risk awareness (2009). Participant \#3 mentions the risk of severe weather and a potential timeframe in which the events will occur. The participant's statement that, "you need to be watching the weather closely from noon on", is far more useful an expression of uncertainty than a statement of "slight, moderate, or high chance of hazardous weather". Because Participant \#3 is trying to make the audience aware of the risk of severe weather, the participant uses a statement that suggests the audience member needs to be watching the weather closely (2009). Risk behavior and risk communication are often highlighted in emergency management research specifically 
focused on communicating the impacts of severe weather. Multiple researchers have found that risk perception is the driving factor in evacuation and mitigation of impacts from potentially hazardous events (Demuth et al. 2009, Morrow 2009, Sarewitz et al. 2003).

\section{Risk, Vulnerability, and Disasters}

Weather forecast communication and forecast uncertainty have been heavily investigated in the meteorological and risk management communities (Demuth et al. 2007, Demuth et. al 2009, Morss et. al 2008, Pennesi 2007). As Demuth et al. $(2009,4)$ suggest, "People use interpretive frames to make sense of things. Citizens' risk perceptions are affected by the norms of the groups with which they identify, just as the risk assessments of experts reflect the norms of their associates." Individual perceptions of forecast uncertainty is highly variable from each person to the next and introduces a high degree of complexity into the process of designing products that aid risk perception among the general public. Morss et al. (2008) specifically contend that the combination of effective uncertainty communication methods and user-oriented products will place uncertainty in the "context of empirical results" (ibid. 975).

...unlike some other contexts involving risk communication, weather forecasts are familiar to most people. Because they are widely available and regularly used, everyday weather forecasts also offer audiences frequent opportunities to evaluate new types of information and learn to interpret new formats. This suggests that the communication of weather forecast uncertainty will evolve through an iterative, dynamic process that connects learning from forecast recipients with product development. (Morss et al. 2008, 975).

While many have focused on the risks associated with the probabilistic likelihood of event occurrence, others have discussed probabilistic risk and its relationship to vulnerability (Cutter et al. 2006, Rouleau et al. 2016, Sarewitz et al. 2003). Risk is broadly defined as the likelihood that an event will be damaging to a population (Tucker et al. 2009). Vulnerability is similarly broadly defined as the 
"potential for loss" in a population, social group, or geographic area (Cutter 2003). Studies in hazard vulnerability focus on the structural characteristics of a hazard area in the context of some type of mitigation plan (2003). Still others have connected vulnerability to the concept of antecedent risk perception and have used risk perception in an attempt to understand vulnerability within a population (Tucker et al. 2010, Sarewitz et al. 2003). Both of these approaches maintain that knowledge of risk is important in order to prevent unnecessary negative impacts to communities, but they equally emphasize that risk perception is the most important element necessary to improve the impact of information provided to populations across diverse and diffuse communities. Following this review, the product created for this research attempts to reduce the boundary of knowledge between experts and the general public by translating storm damage information into 3D visualizations as part of the process of reducing risk to potentially vulnerable populations through improvements in risk perception.

The primary issue faced in this research is not the scientific characterization of hurricane damage, but rather to take scientific characterizations and create meaningful information for populations who lack exposure to the expert frameworks in which hurricane information is conceived. It is the act of translation of the scientific information into visually intuitive representations of damage that requires an understanding of both the physics of storm damage and the psychology of understanding and the subsequent acting upon perceived risk. This area of research arose from the collaboration of scientists from the weather forecast community and social science researchers. Weather and Society - Integrated Studies (WAS*IS) is a program developed by the National Centers for Atmospheric Research (NCAR) and the Societal Impacts Program to coordinate cooperation and product development across the boundaries of specialization between weather experts and social scientists.

As of August 2011, the mission of WAS * IS is to take the expertise of forecasters and climatologists to determine event risk and to distill that knowledge with a group of social science 
researchers to develop more relevant and actionable informational products and warning processes.

Social scientists within the team contributed to the development of weather and climate information, warnings, and forecasts by configuring information products in the light of the population for which the products were designed. Some critical understanding of the audience in question is necessary in order to most appropriately and effectively inform a population about impacts of, and vulnerability to, extreme weather events. In short, WAS * IS represents the critical nexus of atmospheric expertise and social science that aims to produce meaningful guidance for the general public to make decisions about extreme weather events.

It is proposed in this research, and supported by publications from the weather forecast community at large, that the general public is the most important audience to reach with effective emergency weather information to support appropriate decision making (Demuth et al. 2007). WAS*IS attempts to develop intuitive information dissemination products that incorporate the findings of social science in order to improve understanding within the specified audience. Weather information is primarily conveyed to the general public through broadcast media television and web sources, weather forecasters, and private meteorologists (Sandy Assessment 2013). There are a variety of different stakeholders and organizations that contribute to data repositories that store information about the atmosphere that can be analyzed to infer how and where an event will take place. Analytical products are often embedded into the latest forecast visualization software packages to create graphics that can be grasped and understood more readily by the general public. As discussed in several uncertainty and risk communication papers, the methods of information dissemination preceding and during an extreme weather event can vary greatly from one forecaster to the next (Morss et al. 2008, Demuth et al. 2007, Demuth et al. 2009). In weather forecasts, data management, atmospheric analysis, and innovative communication methods combine to prevent extreme weather from creating a significant burden on the economy and to reduce the probability of extreme weather events leading to fatalities. In addition, as in 
the case of Superstorm Sandy, operational forecast products are predominantly obtained from NWS/NOAA and affiliated government data sources, which at times challenges the ability to handle server requests at NOAA/NWS data storage centers (Sandy Assessment 2013). WAS*IS suggests that research in the social sciences can contribute to the improvement of operational forecast products by incorporating "meteorological research and societal needs" as part of the process of product development (Demuth et al. 2007, 1729).

\section{NOAA Assessment Reports}

The NOAA assessment of Hurricane Sandy suggests that the NWS should develop "clear and compelling motivation" through watch and warning products for intense storms (Sullivan 2013, 3). The authors of the Sandy assessment note that a key theme in disaster preparedness is to improve communication and dissemination of storm related information to the public. In surveys of individuals affected by Sandy, there was a consistent call for "information about pending events" to be more readily accessible for emergency managers and the general public (Sullivan 2013, 42). Respondents to the NOAA surveys suggested that briefing packages sent by local NWS weather forecast offices were valuable in helping them to prepare for the event. However, the communication of expert information about the possible effects of Sandy provided an example of the problems associated with effectively motivating populations to act in the face of challenging weather events.

NOAA has established that social media outreach was particularly important during Sandy and future storm scenarios they suggested will need to respond to the demand established by the public to provide information through social media technologies (Sullivan 2013). NOAA websites are still the most important resource during a storm, receiving 1.3 billion hits throughout the course of Hurricane Sandy $(2013,4)$. Even with social media outreach and web access, user groups still noted the need for more effective storm risk communication which was deemed necessary to better inform communities about 
potential storm effects to their area $(2013,23)$. The current strategies for making populations aware of approaching weather events are largely based on 2D cartographic representations, of which the best example is the weather radar map that shows an image of a hurricane approaching the coastline and highlights specific risk areas (Figure 1.1 and 1.2). Although these representations illustrate the meteorological elements of the event, they fail to communicate what will happen on the ground as a result of the event striking a certain area, not least because local geographies can vary significantly. Even in the case of the hurricane threat map, "action" can mean different things to different groups of people across the geographic area highlighted. Improving methods for communicating the effects of weather disasters could help the public to better understand strategies to prevent economic damage and loss of life.

Pielke et al. (2008) explain that contrary to popular thought there is no long term trend of increasing damage from hurricanes in the United States, though there is an increase in the population and infrastructure susceptible to hurricane damage. Nicholson-Cole (2005) suggested that using computer aided visualization will help motivate individuals to better understand how they contribute to environmental change and how they can affect changes in the environment through their own actions. Similarly, individuals might utilize computer aided representations of weather disasters to understand the most important ways in which to prepare and how to avoid the direst consequences of a disaster. In the NOAA report on Hurricane Sandy, there are two sections that refer to public response and the articulation of impacts (Sullivan 2013). Communication with the public was seen to be a key element of several government organizations including the Center for Disease Control and Prevention, the Environmental Protection Agency, the Federal Emergency Management Agency, and the Department of Homeland Security. Maps that estimate storm surge related flooding were considered to be particularly useful in helping the public to understand the relative risks of a weather event. In the case of Hurricane Sandy, rail cars in Connecticut were saved from destruction because of the information provided by such 
storm surge maps (2013). These visual products place predictions in a context that can be more intuitively understood by the public, but 2D representations still often lack the vivid imagery that allows people to associate events with their personal space and understand the ramifications of different types and magnitude of events. Flooding and related impacts can be difficult to convey if an individual cannot associate and find affinity to the event being portrayed and affecting their local neighborhood.

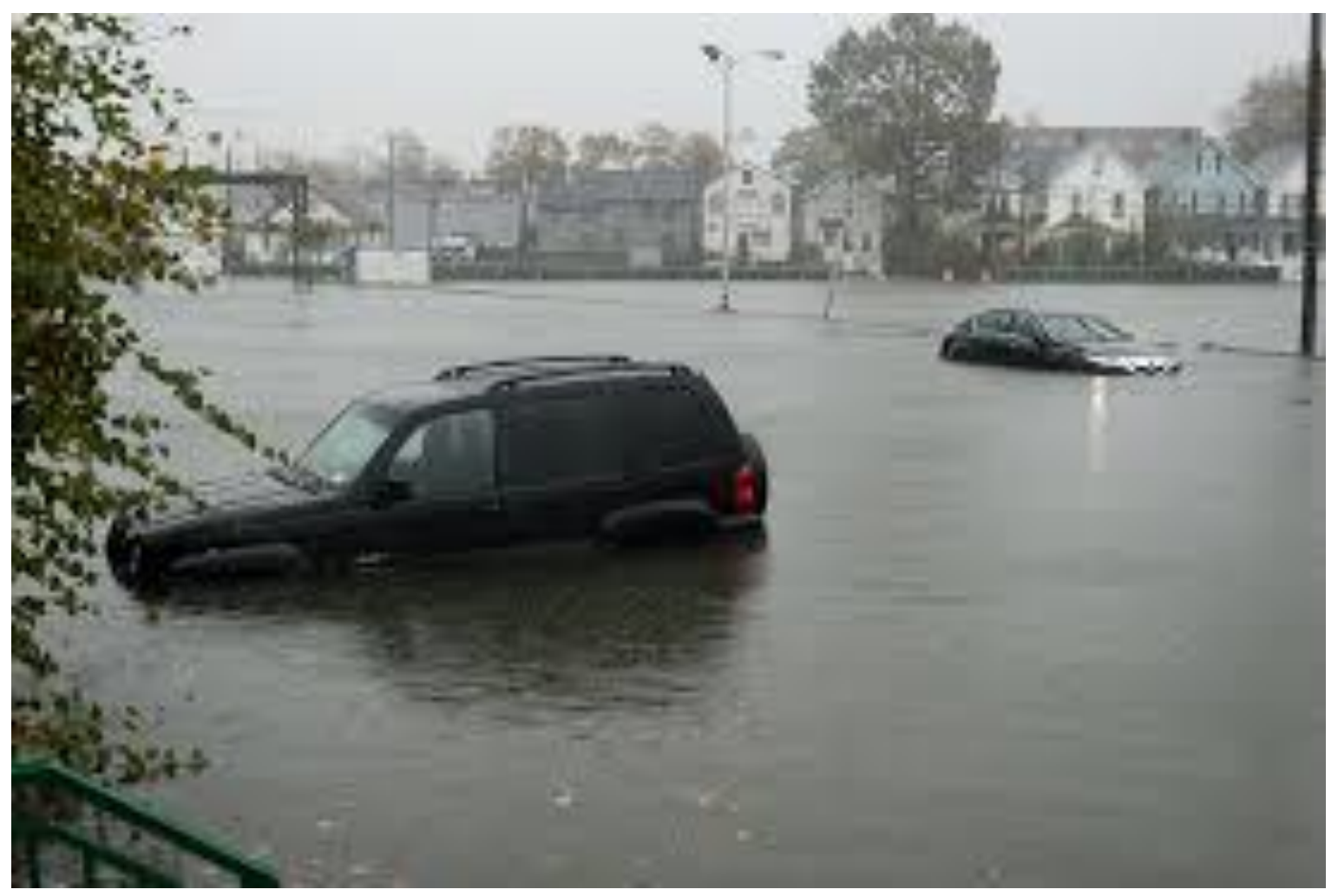

Figure 2.1 - Car partially submerged in Hurricane Sandy floodwaters. (Source: WFUV) 


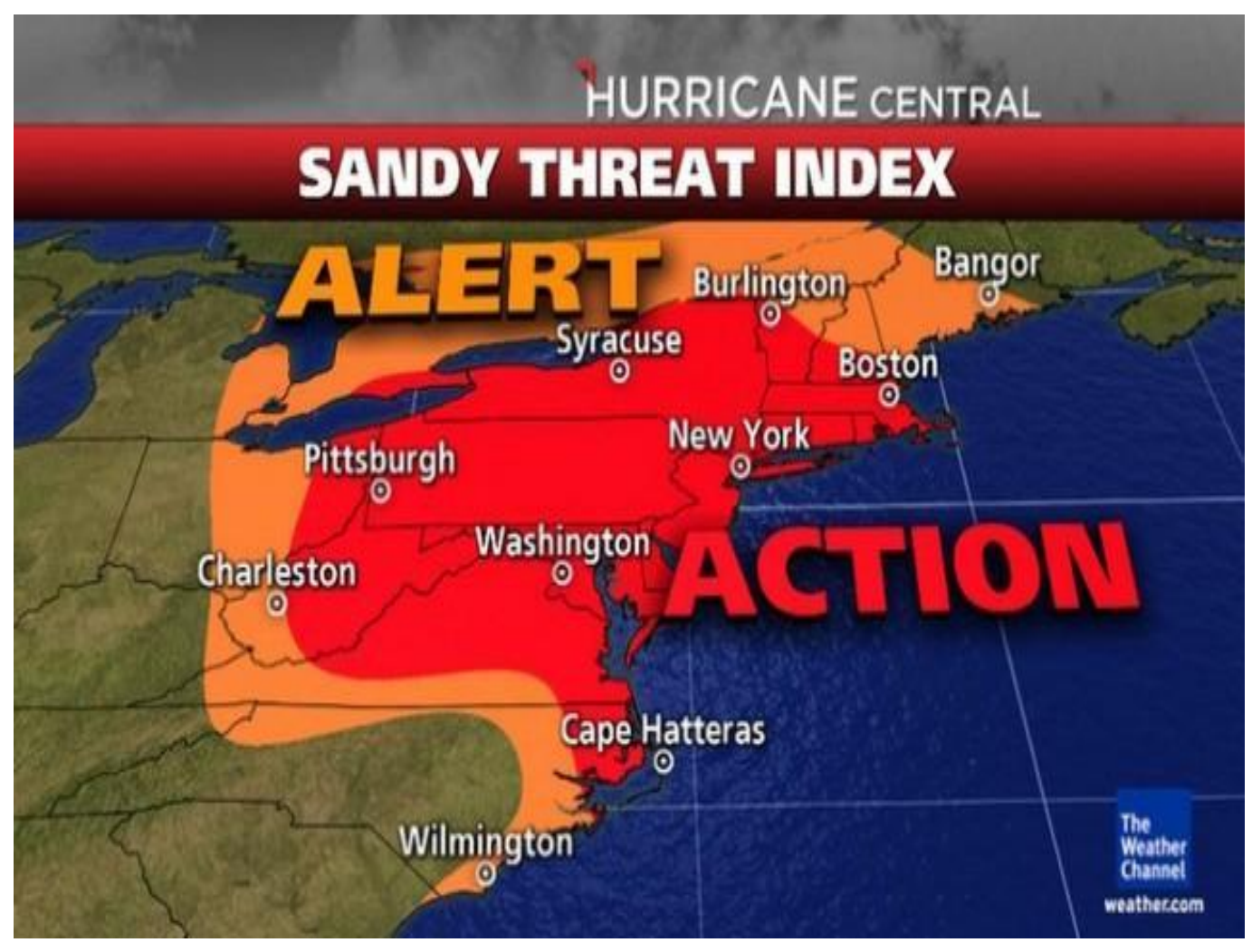

Figure 2.2 - Hurricane Sandy threat index cartographic representation. (Source: The Weather Channel, Hurricane Central - Sandy Threat Index)

Weather information simultaneously occupies the spaces of high technology and general knowledge. It is of importance to anyone to be aware of the atmospheric processes that determine the daily weather. Long term projections of weather can help numerous areas of commerce to allocate resources and plan logistics effectively. In the sense of general knowledge, weather occupies a space which can be explored by experts; as well as through the individual experiences of the layperson. The United States relies heavily on standards-based government data to communicate with the public about weather events. Through a diverse and evolving network of organizations, the weather enterprise in the United States attempts to understand and mitigate weather processes and impacts around the world. NOAA is an arm of the United States Department of Commerce, responsible for the NWS. The NWS collects weather data, assembles graphical products, and communicates with the general public when 
weather becomes dangerous. The NWS uses an organization known as the National Centers for Environmental Prediction (NCEP) to house information products and analysis for hydro-meteorological prediction. NCEP is composed of NCEP Central Operations (NCO), the Aviation Weather Center (AWC), the Climate Prediction Center (CPC), the Environmental Modeling Center (EMC), the National Hurricane Center (NHC), the Ocean Prediction Center (OPC), the Storm Prediction Center (SPC), the Space Weather Prediction Center (SWPC), and the Weather Prediction Center (WPC). NOAA, NWS, NCEP, NCO, AWC, CPC, EMC, NHC, OPC, SPC, SWPC, and WPC are all acronyms that represent the various organizations responsible for researching weather events and communicating their impacts to the residents of the United States and beyond. The problem addressed by this research is the boundary between scientific expertise and the ability to translate expert information into a meaningful form to support public decision making during times of extreme weather. This research leverages computer generated software architecture and 3D GIS to translate expert information that communicates risk and provides meaningful decision support to the general public in times of extreme weather. 


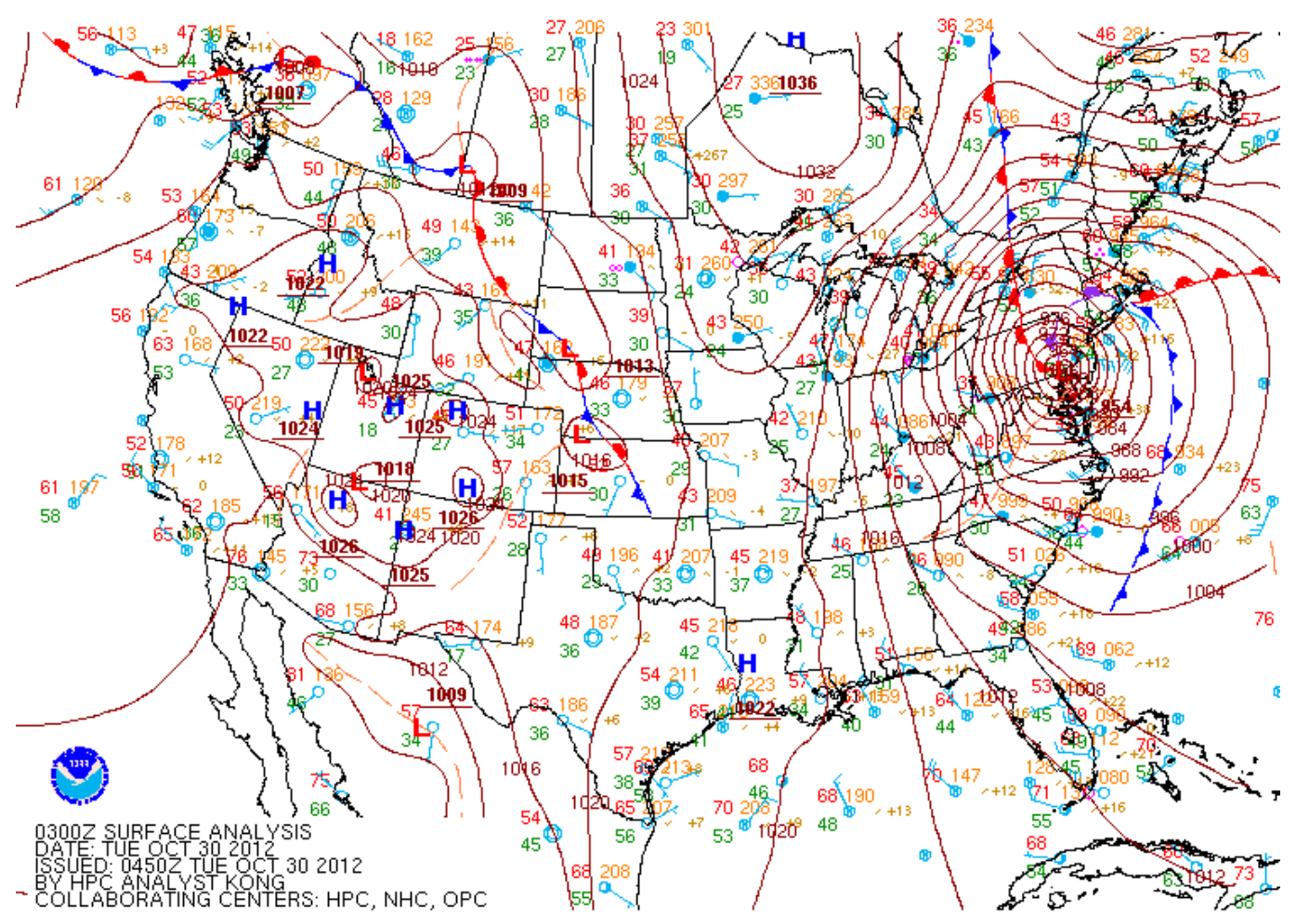

Figure 2.3 - Expert view of Hurricane Sandy at landfall WPC, HPC, NHC and OPC collaborating centers, Source: Weather Prediction Center Surface Analysis, Oct. 30, 2012

As research diverges in context and expertise, the ability to coordinate decision making and the sharing of information to improve outcomes increasingly relies on technological innovation. A Decision Theater is a space where a suite of information products can be displayed simultaneously to an audience comprised of experts from various disciplinary, policy, and management backgrounds. Various severe weather based scenarios can be explored in the Decision Theater and decisions made based on the insitu collaboration of stakeholders. In his discussion of boundary organizations, David Guston explains that boundary objects are situated between two opposing social worlds as in "science and non-science" (Guston 2001, 400). In the current context, innovative visualization through GIS technology becomes the object that enables various groups to interact with the same information. But how do the creators of high impact technological communication methods know that they are succeeding in reducing the 
boundary of knowledge between groups? In the case of White et al., it was necessary to evaluate boundary objects with their "credibility, salience and legitimacy" in mind in the Arizona State University Decision Theater to show how water managers can make decisions in a dynamic environment that incorporates multivariate data $(2010,219)$. Cartographic representations of weather can be considered boundary objects because they represent scientific observations of the atmosphere that are used by scientists and nonscientists alike. Weather maps and warnings, like other boundary objects, depend on the acceptance of both scientists and nonscientists in order to be effective: simply put, scientists make predictive weather maps to advise the public and non-scientists about the use this information to make personal decisions.

At times, antecedent risk of extreme events has been well characterized by subject area experts, such as the case of Hurricane Sandy and the publication of a storm surge risk assessment two years prior to the event. Nonetheless, the impacts of the storm surge from Sandy created immense social and economic disturbance (Lin et al. 2010). The implication of boundary objects in aiding public awareness of pre-disaster risk encourages the general public and professional experts to communicate with each other. Experts can store relevant forecast information in a 3D geographically-referenced database while the general public could benefit from visualizations of real world data and real storm scenarios. Given that 3D visualizations of disaster landscapes, especially in the context of the local, can leave a lasting impression on viewers and influence their perception and response to weather events, it is possible that changing the mode of information display from text and 2D weather maps to 3D models of the local landscape will reduce the knowledge boundary between experts and the general public. Ideally, people will be able to grasp the scale and magnitude of effects in a way that facilitates their awareness and overall perception of risk which thereby should improve their decision making. 
Visual communication and work in 3D geo-visualization could arguably enhance the public predisaster risk awareness by effectively communicating the most pressing issues through pseudo realistic models of the local landscape as potentially impacted by an event. This sense of place could allow people to appreciate disaster outcomes and to make wise decisions early (Crampton 2001). These decisions are often made within a limited amount of time and thus rapid communication is an important factor of any product designed to inform decisions about potentially disastrous events. 3D geographies offer opportunities to communicate information to broad audiences in an efficient and intuitive manner about a variety of weather events and give the experience of being in a place or space. This research takes the problem of representing events in 2D space and attempts to incorporate 3D models to display the visual impact of weather events on localities contextual to an individual. 


\section{Chapter 3 - Methodology: embedding hurricane damage in a 3D GIS}

Information dissemination through the use of 3D geo-visualization requires several steps to design and embed model specifications into the final product for the benefit of the end-user. In this research, ESRI City Engine was used to model buildings and landscapes according to some hypothesized impact from certain weather patterns and predicted storm damage and these are generated using Computer Generated Architecture (.cga) code. In response to the many calls made by NOAA and NWS for more rapid information dissemination, this visualization uses the framework of expert communication to translate storm damage warnings from text descriptions to a visual depiction of a neighborhood that has been impacted by varying categories of hurricanes.

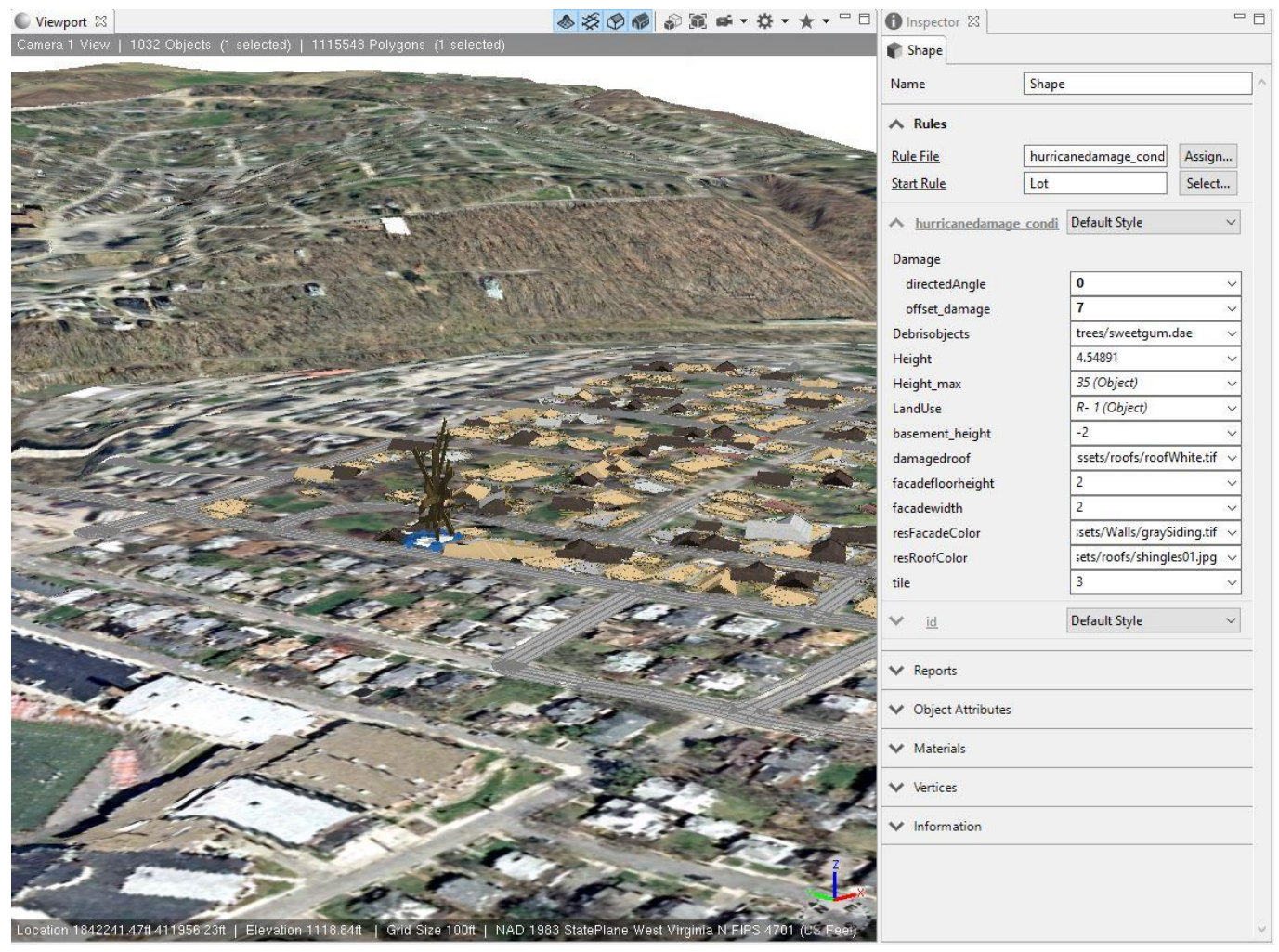

Figure 3.1 - One of many bugs addressed in the development of the .cga script Source: author screen capture, 2017 
Throughout the research process, multiple design decisions had to be made about how and when to display certain attributes of the hurricane storm damage not least to simplify the multitudinous polygon counts within CityEngine, and thereby reduce development and run time operations. In addition, across weather forecasting and weather warnings in general, wind-borne damage has the highest transferability for use in other weather warning products across the geography of the United States. Hurricanes, tornadoes, and so-called straight-line winds associated with convective systems present a threat to the general public in most areas of the country and thus wind speed is used in most warning systems.

CityEngine draws heavily on GIS and 3D modeling in order to visually depict hurricane damage. A seven step process was employed in this study to develop viable products in the most effective manner:

Step 1: Record descriptors and references to physical assets within the built environment

Step 2: Catalogue specific damaged components from descriptions on Saffir-Simpson Hurricane Wind Scale and photographic evidence of storm damage (Figure 3.3)

Step 3: Assemble building footprint data, aerial imagery, and create a digital terrain/elevation model for .cej (CityEngine Scene File)

Step 4: Procure assets, models, and textures and transfer for use in CityEngine Workspace

Step 5: Develop relationship between visually depicted damage and programmatically dictated values of "Damage" slider created in HurricaneDamage.cga 
Step 6: Coordinate progressive, procedural destruction of buildings in CityEngine and include 3D models, building damages to roof and structural elements, spread debris throughout scene (see bugs and parameterization in Figure 3.1)

Step 7: Parameterize relationship between .cga damage handle and depicted damage elements in CE to provide realistic representation of impacts.

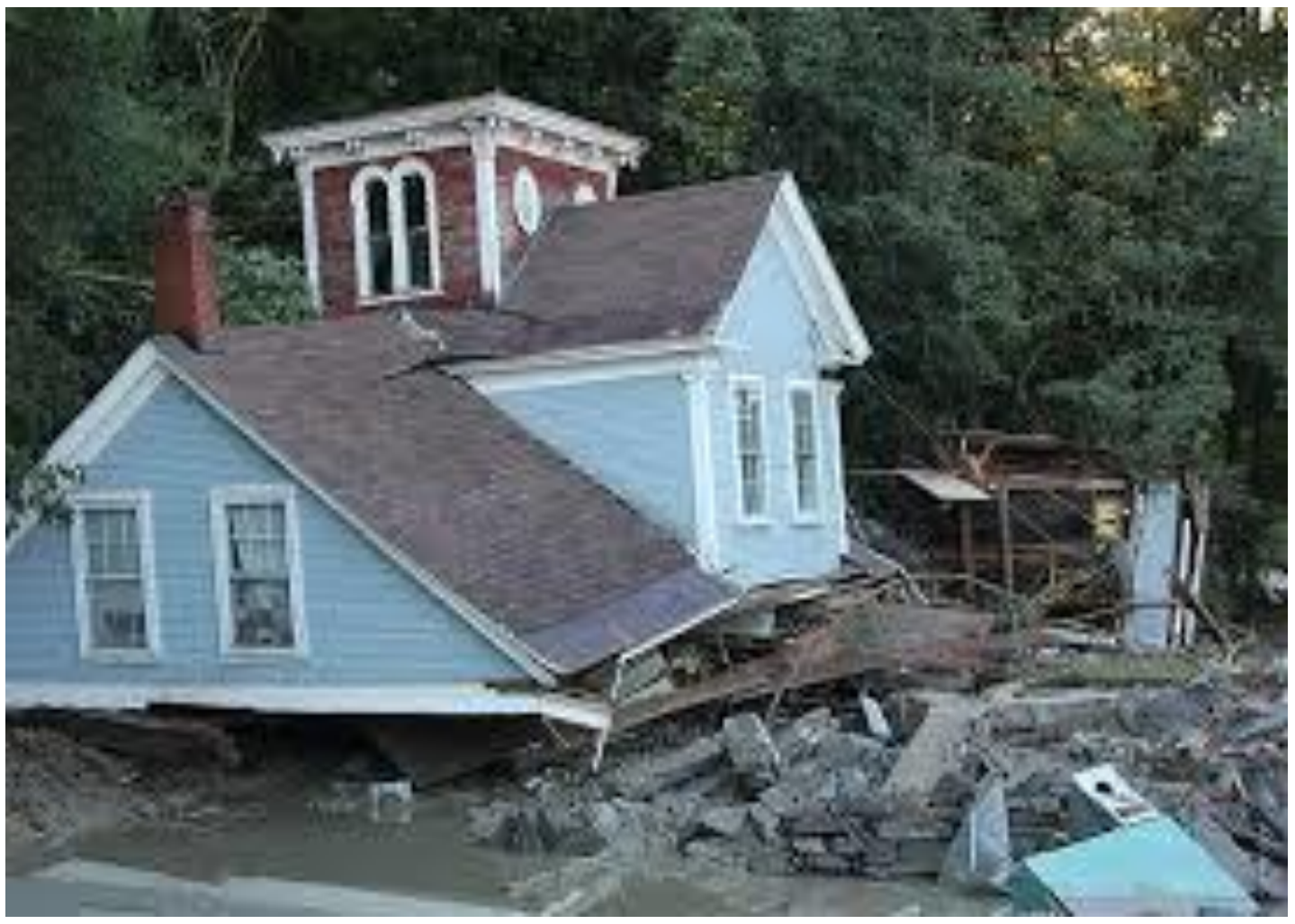


Figure 3.2 - House moved from foundation, exterior buckling of walls Source: http://www.climatecentral.org/blogs/wild-weather-a-new-normal-insurancecompanies-must-act-14937, April 2017.

CityEngine is a procedural rule-based 3D GIS software that allows users to specify the characteristics of 3D objects within a user determined polygon space and create virtual 3D objects to represent entire city landscapes using GIS data (http://www.esri.com/software/cityengine). CityEngine has been used by planners, architects, and designers to create realistic models for the investigation of transportation, urban development, and 3D geoprocessing for planning applications (Müller et al. 2006, Schwarz and Müller 2015). The primary contribution of CityEngine software is its capability to create a $3 D$ virtual scene that is embedded within real world geography generated by GIS. CityEngine models can be exported into gaming engines (Unity) and other ESRI software, such ArcGIS Pro, to add physically realistic components or to deepen geographical context and analytical power. The various built-in functions and programmable .cga code can be leveraged to depict numerous scenarios and geographies for the development of direct, visual, and intuitive communication products.

A significant portion of the time invested in this project was spent troubleshooting various evolving development versions of ESRI CityEngine (http://www.esri.com/software/cityengine). The almost beta nature of the CityEngine software release and resulting software issues with install, licensing, processing, and other general bugs severely impacted the progress and scope of this research. These issues include but are not limited to: computer crashes under high polygon counts, license expiration and issues in renewal, installation of updates, and general mismatches between current versions of software and procedures detailed in ESRI provided tutorials and manuals. The progress, and perhaps scope, of this project and its outcomes would arguably have been greater if CityEngine had functioned more smoothly from the outset concerning installation, data development, and implementation. Development time could have been focused more on modeling and depicting scenarios, collecting data, and building scenes for real life geographies rather than on resolving chronic 
and recurring software bugs. Nonetheless, testing and evaluation of CityEngine as a platform for this modeling was part of the goal of the research and thus the project continued to push the development of the CityEngine system. Ultimately, the demands of CityEngine even exceeded initial computational specifications though a significantly higher performance computing capability did improve performance and efficiencies in modeling and scene development by a significant margin. A portion of the development which took an estimated 100 man hours to complete with a lower performance computer was completed in one hour with a special purchase higher specification machine. The specifications of the computer hardware are included in the Appendix III.

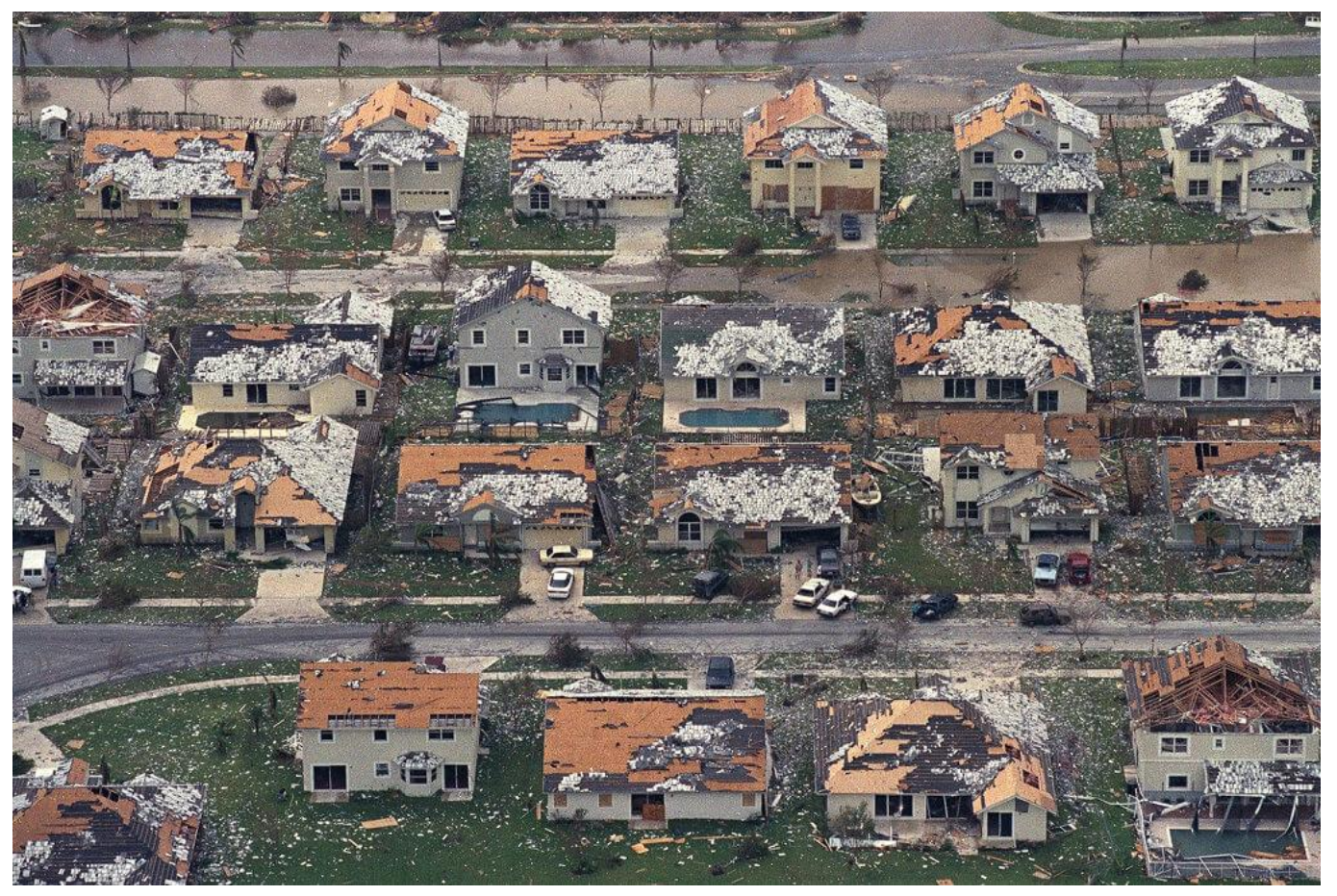

Figure 3.3 - Photo of neighborhood scale destruction, shingles and cars Source: Engineering Express https://www.engineeringexpress.com/forensicengineering/, March 2017. 


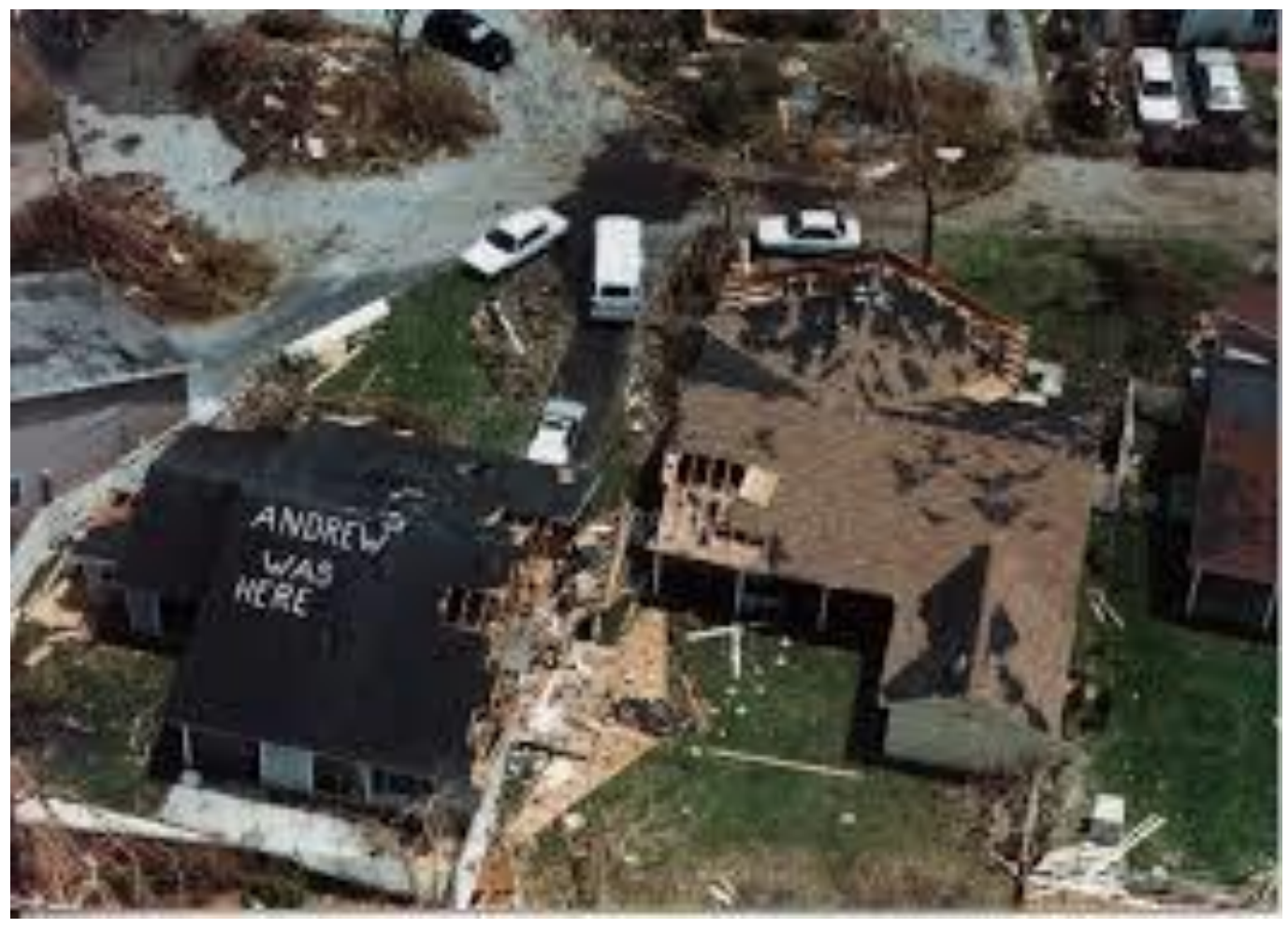

Figure 3.4 - Damage from Hurricane Andrew, superficial and structural damage Source: National Hurricane Center Photo Archive, http://www.nhc.noaa.gov/1992andrew.html.

Input specifications for building damage models are determined using wind speeds and text descriptions of damage from the Saffir-Simpson Hurricane Wind Scale (Saffir-Simpson 2013). In addition, photos of hurricane damage were used to augment the development of geometric damage parameters in the .cga code by verifying model geometry using photographic evidence of post-event storm damage (Figure 3.3, 3.5, 3.6 and 3.7). After the process of geometric parameterization is complete, a scene is built within CityEngine comprised of a digital terrain model draped with aerial imagery to represent the texture, color and topography of the area under study. In CityEngine a scene is indicated by the .cej file extension. A scene file is a conglomeration of the different data elements outlined above that are used to create a scene for a geographic area and generally includes a terrain model, 3D models of buildings, and an aerial image clipped to the scene extent. The digital elevation model (DEM) is overlaid on a 
CityEngine predetermined pixel grid with a maximum 1024 x 1024 resolution. This limitation in scene size and extent can be troubling for projects using high resolution imagery and elevation data and will eventually limit the quality of the image that can be overlaid, as can be seen in the pixelated image covering the terrain in the hurricane damage visualization (Figure 3.6).

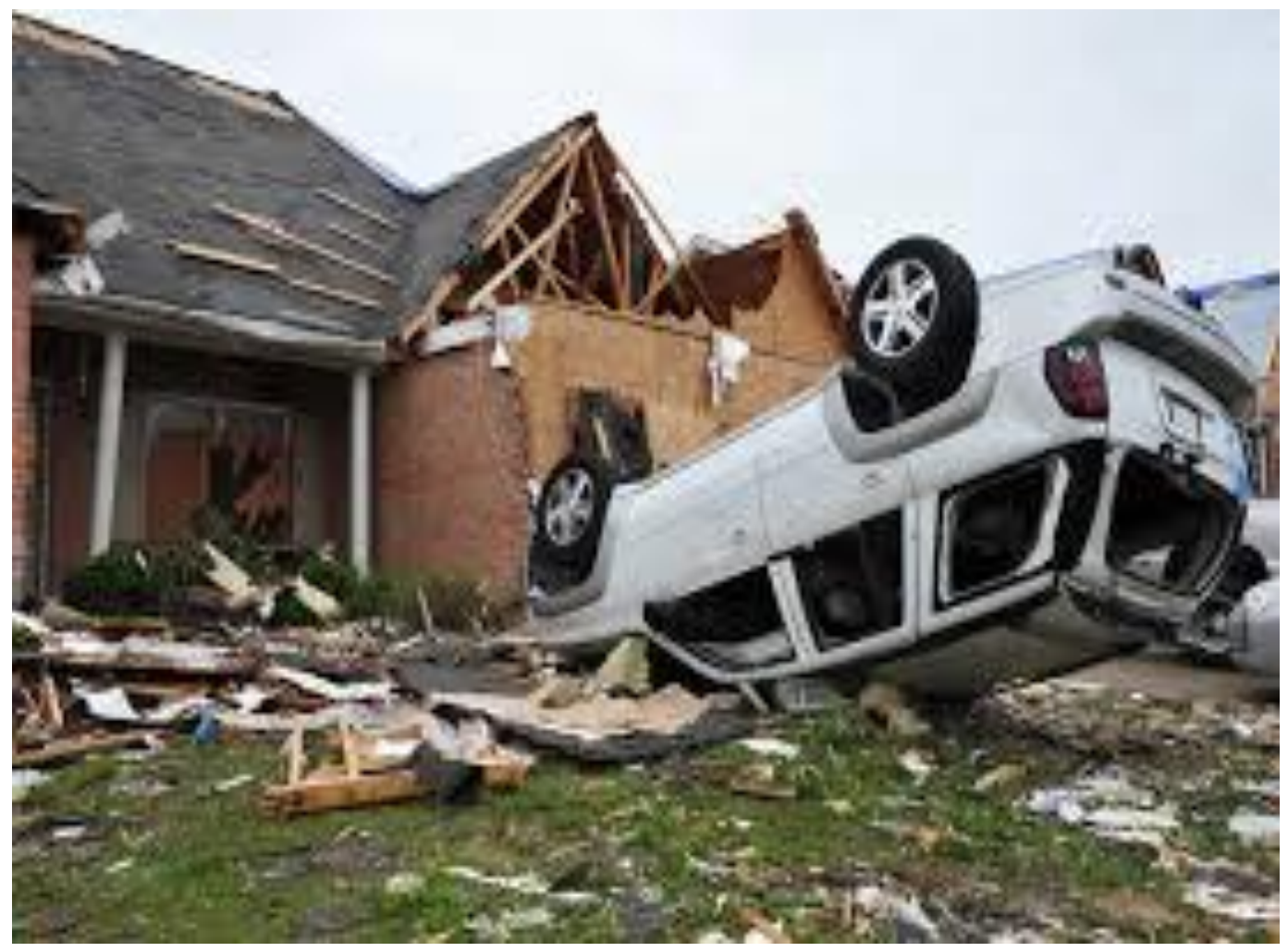

Figure 3.5 - $\quad$ Car flipped, gable end destroyed, roof decking partially intact Source: Clark Insurance, https://goclarkinsurance.com/wpcontent/uploads/sites/21/2015/10/storm_damage_homeowners_insurance.jpg April 2017.

This project used Morgantown, West Virginia as a test base to facilitate development of realistic 3D scenes and models of building damage. As of CityEngine 2016.1, the Get Map Data interface allows a user to select building footprints, elevation data, and imagery using a polygon, rectangle, circle or lasso tool. This was a monumental improvement for this application relative to earlier CityEngine versions 
because rule files and packages could now be readily applied to user-selected geographies. In the case of this research, the Get Map Data was not used because of sparsely populated Open-Street Map (OSM) building footprints in geographically relevant coastal areas. Data were already compiled in a CityEngine project file for the geographical area of Morgantown, WV by this author and fellow class students in the Department of Geology and Geography at WVU. This data were used because of its appropriateness and sophistication relevant to the goals of this study. Modeling the 3D buildings under the scenario of progressive storm damage scripts were subsequently developed through .cga.

This area of Morgantown, WV is not historically at risk from the direct impacts from a hurricane, but irrespective, the 3D building models and scene components are similar to an inner-coastal waterway or bay likely under threat from hurricane damage in a coastal locale. The building and landscape design for the scene were constructed to reflect an area under threat of hurricane damage, to which were added elements of sub-tropical and temperate coastal environments such as trees and photographic textures. Importantly, in real-world contexts, the building footprints, property boundaries, and terrain height maps can be edited to depict a variety of different geographies on which the current .cga code will continue to operate. For example, building footprints and tax parcel datasets curated by a local government can be attributed and the geometry and texture of computer generated buildings can be produced based on this .cga code.

The visual and graphical damage displayed in CityEngine is again achieved through the use of .cga code. The level of damage arising from each category of hurricane and the resultant impact on the modeled geometries of buildings is undertaken within one procedural rule file developed in CityEngine acting upon a set of 3D models and photo textured assets used to populate the scene. Additional CityEngine assets imported into such a scene included street furniture, telephone and electrical poles and lines, trees, urban infrastructure features and materials and other elements of the city that would 
likely suffer damage from a hurricane. In order to optimize the time it took CityEngine to complete a scene, many of the asset models had to be removed because the polygon counts exceeded 100 million and ultimately prevented the scene from being rendered and displayed (Figure 3.9).

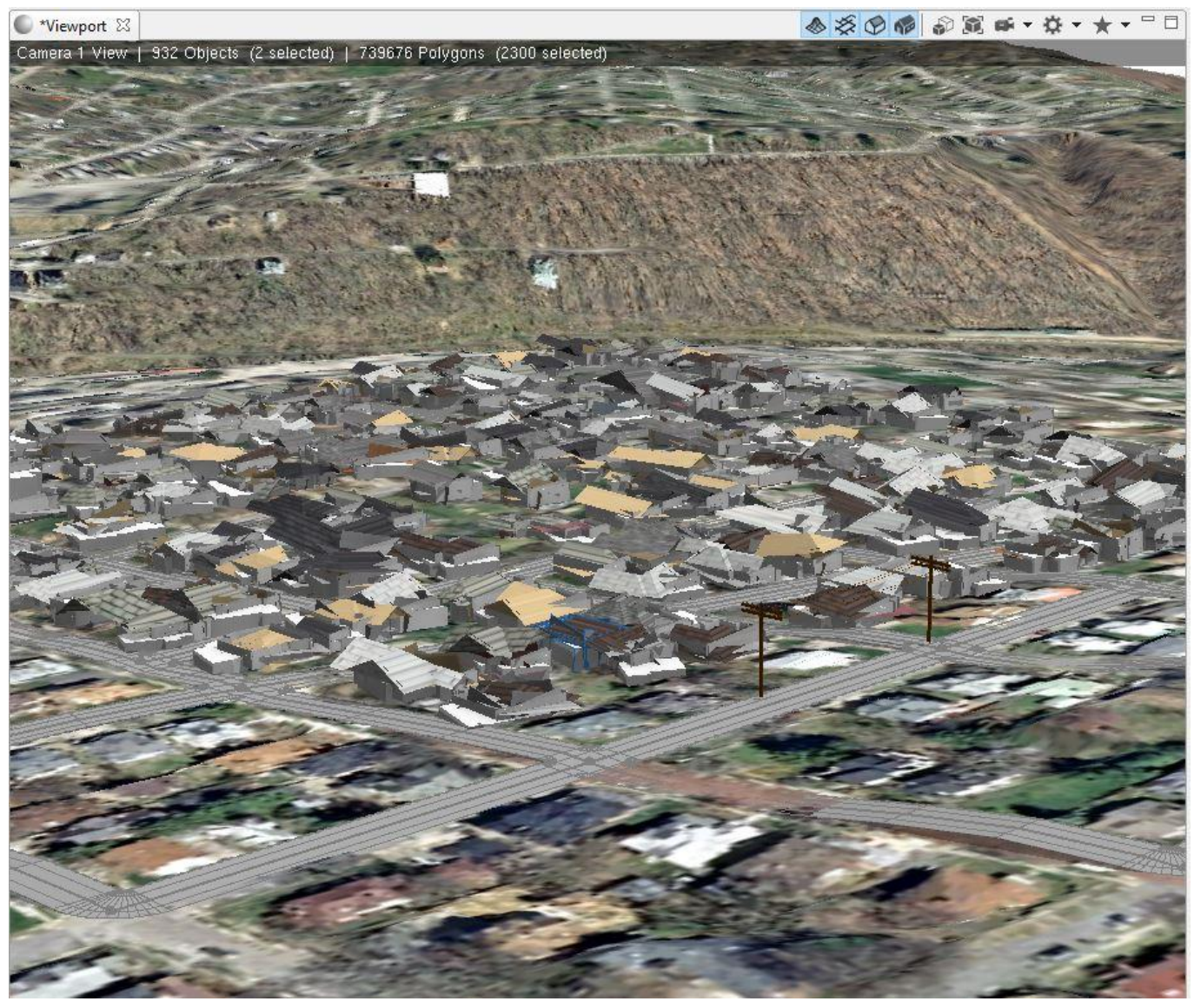

Figure 3.6 - Neighborhood scale destruction of shingles/roof in CityEngine 2016.1 Source: author screen capture, 2017. 


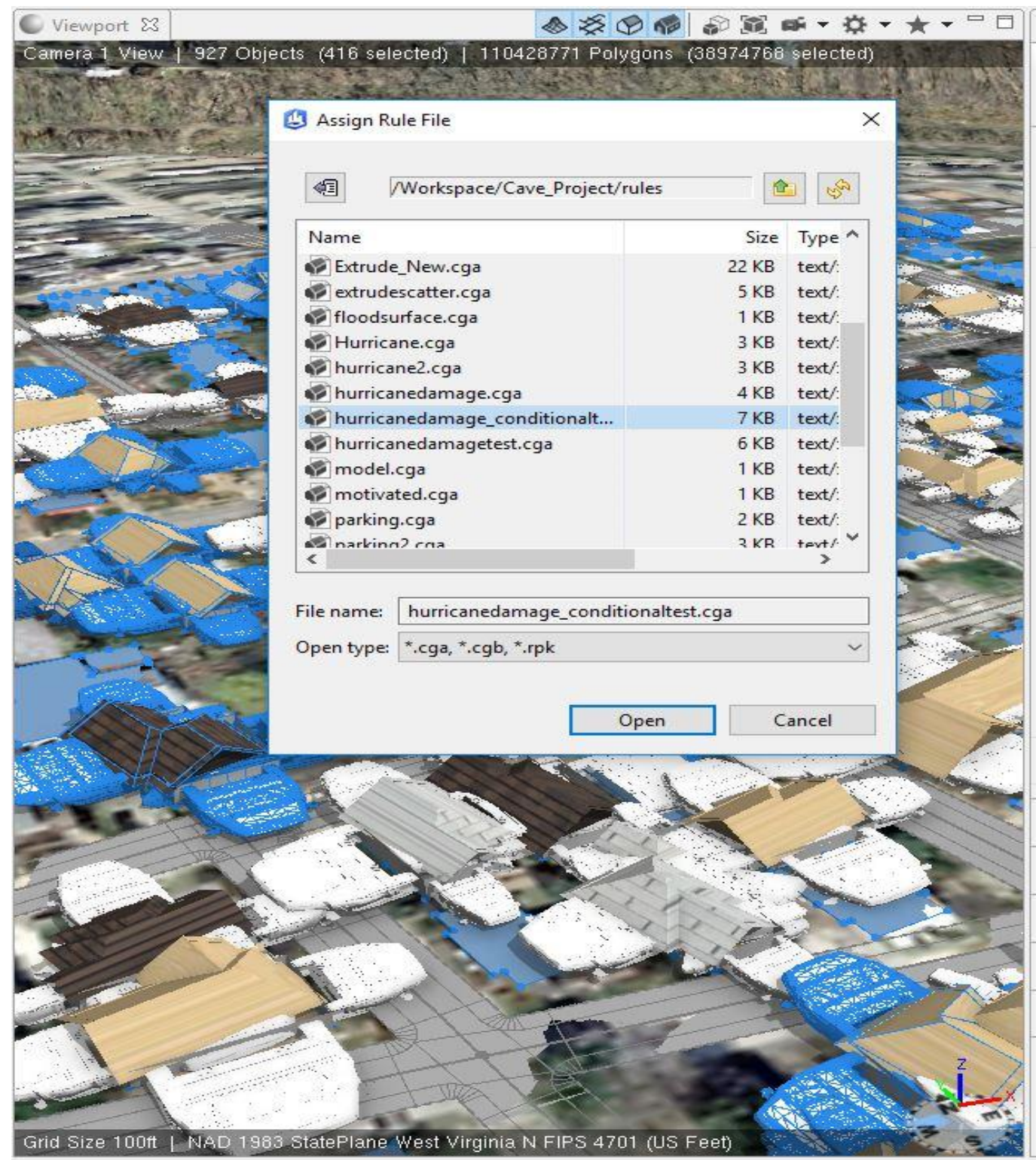

Figure 3.7 - Over 110 million polygons displayed attempting to add cars Source: author screen capture, 2017

Damage to buildings, landscapes, and infrastructure arising from a hurricane can be complex and extensive. The .cga model developed here focuses on specific and locally relevant examples of damage in order to convey the severity of five hurricane categories on the built environment. These 
elements, in conjunction with depictions of flood waters, create a relatively accurate depiction of a built environment undergoing severe storm impacts that arise when caught in the path of multiple hurricane categories.

There are multiple elements of the built environment frequently referenced in the SaffirSimpson Scale to indicate potential storm intensity. The Saffir-Simpson Scale reflects the potential damage to buildings as an indicator of the severity of a storm. These indicators might include "roof shingles will be removed" or "roof decking will be removed or severely damaged". It is evident that these indicators have been identified from hard experience gained from post-hurricane effects typically found in damaged areas and from reviewing the images of hurricane damage collected by news agencies and post-storm aerial image surveys conducted by government and aid agencies (Figure 3.4). Debris piles in post-storm photographs typically consist of an assortment of home and household items along with construction materials, trees and vegetation, and sometimes automobile damage. Homes and cars are highly valued pieces of personal property and help reinforce the notion that individuals in the area affected by the storm stand to lose significant quantities of personal property in the event of an extreme or damaging storm, let alone personal safety. The text descriptions from Saffir-Simpson are the primary components used to construct and populate the models; not least because these are the descriptions available to the general public if they search "What is a Category __ hurricane?" (Google Search Result). As a result, three typical 3D object types were included in the study; residential buildings, trees and vegetation, and additional elements embedded in the built environment such as street furniture and cars (Figures 3.8 and 3.9). 


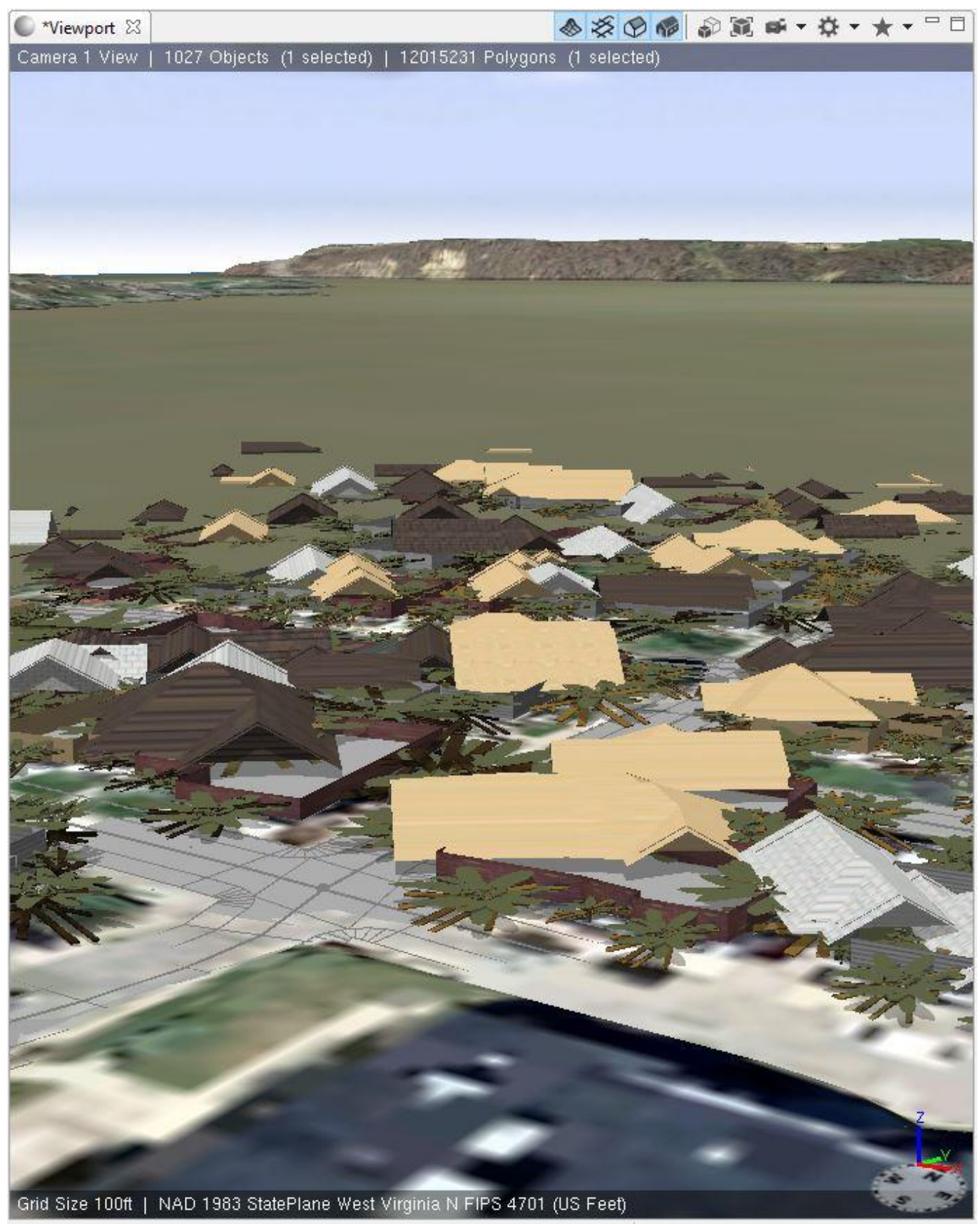

Figure 3.8 - Neighborhood with trees and flooding depicting potential damage from Category 4. Source: author screen capture, 2017. 


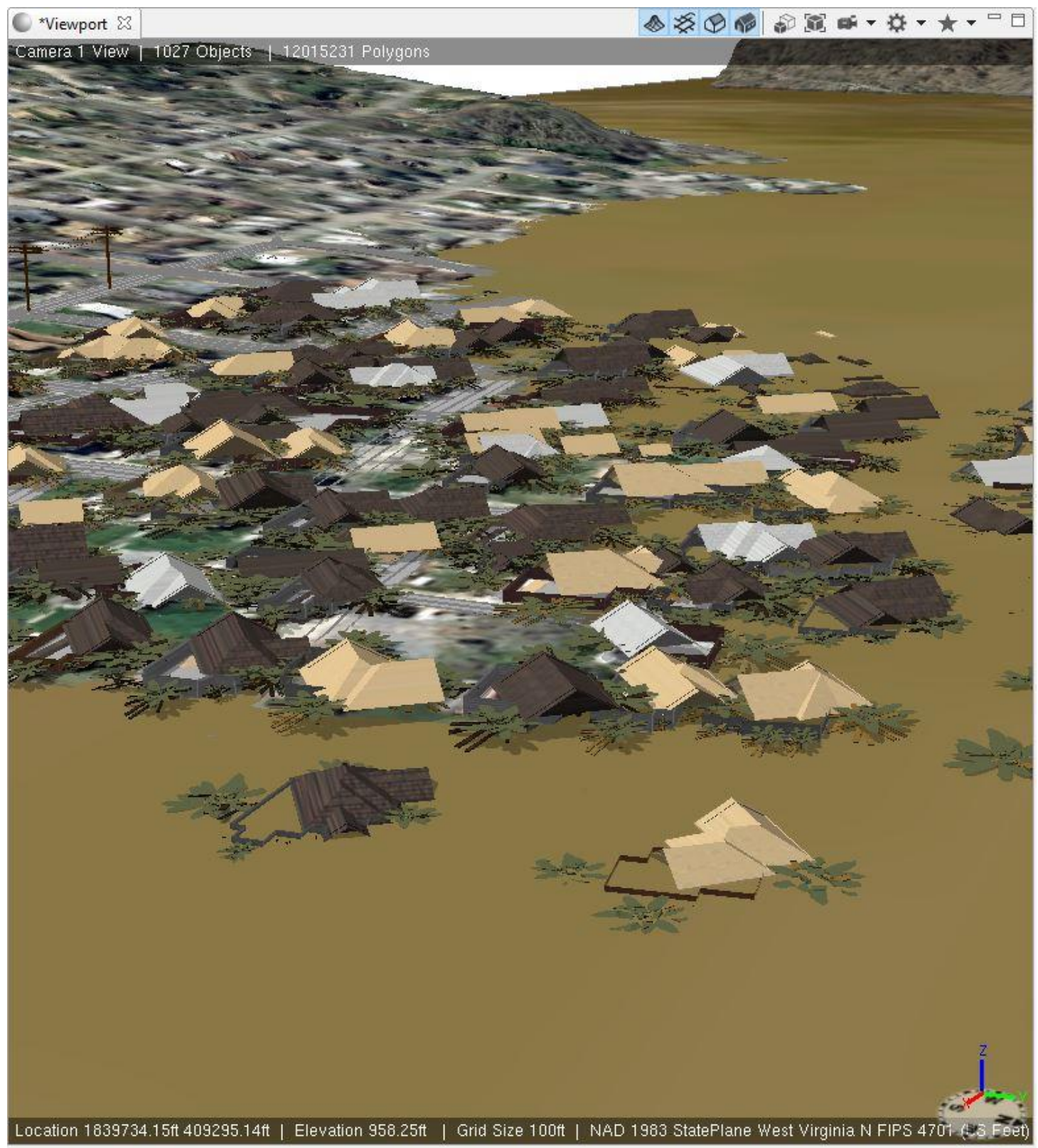

Figure 3.9 - Neighborhood flooded with storm surge Damage 6.5 Source: author screen capture, 2017. 


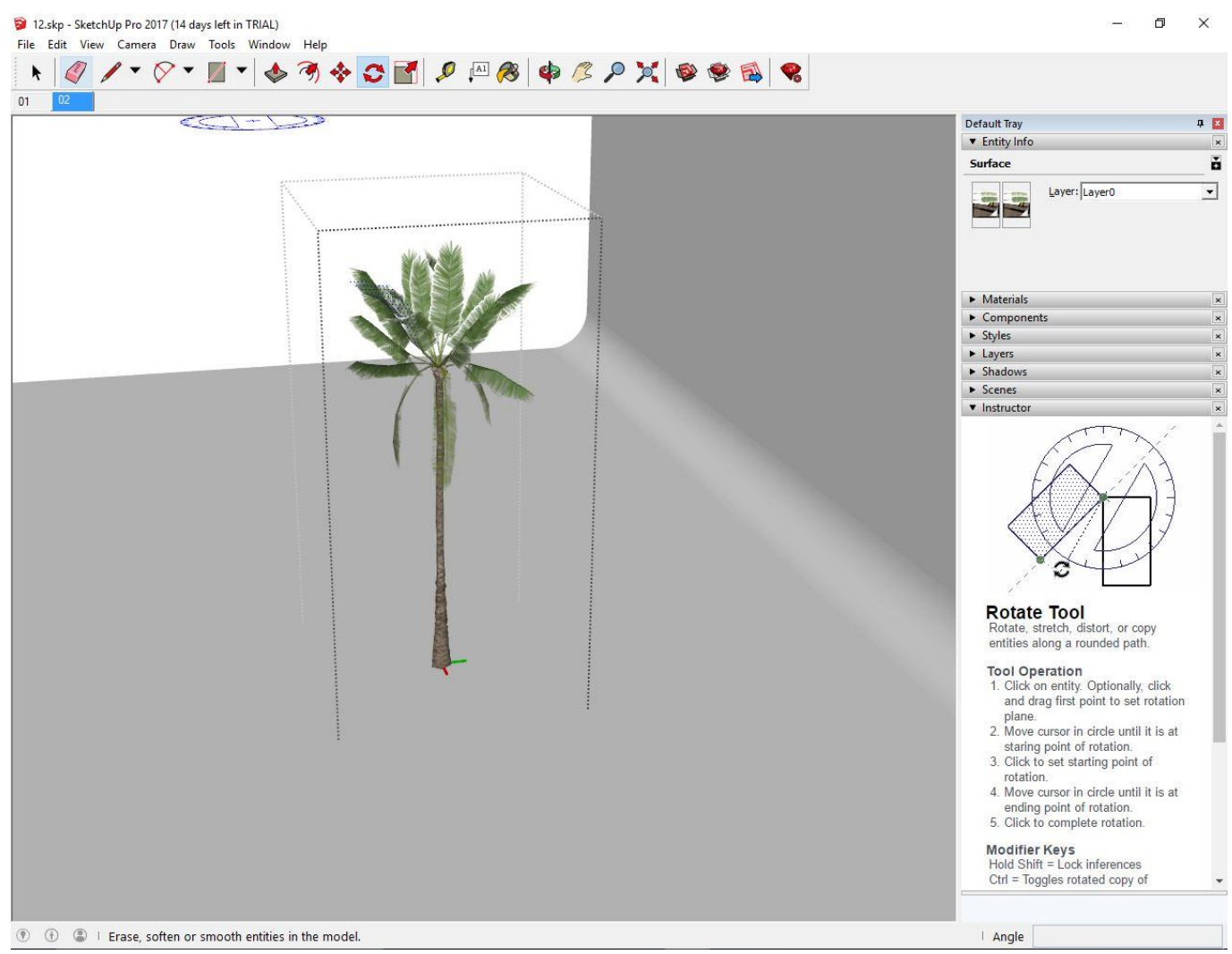

Figure 3.10 - SketchUp Palm tree model ready for import before geometry is reduced Source: author screen capture, 2017.

Trees are frequently found in residential communities because they provide shade and aesthetic appeal. Trees also act to slow wind speeds by contributing to surface friction, and their roots help to reduce the impacts of erosion by holding soil in place (see example tree model Figure 3.10). Hurricane force winds are often described by incorporating the degree of damage to the trees within a neighborhood to communicate potential damage at the predicted given maximum wind speed. This depiction helps individuals in the area under warning to understand the force of the storm and the potential impacts to people and property in its path by giving them a benchmark: 'If winds are high enough to blow a tree over and through the air, what's going to happen to you and your home?'. 
The most critical layer in these scenes is the building footprint information for the city or area in question. Using this data the .cga code constructs geometric model features in association with polygons in the building footprint shapefile data (ESRI shp). Building-footprint polygons are the primary object upon which the 3D models are constructed, along with associated models of other landscape elements such as trees and debris objects which are also connected to building footprints through the residential façade $(/ /<$ resFacade $>/ /)$. The building footprints are representative of the location and size of each of the structures in the study area. As discussed later, using local and personal property represented in a post-event damage visualization helps to enhance the relevance and individualized impact of the graphics by placing the user in the context of a local virtual geography. The CityEngine .cga code shows the impacts of these events through assets/objects in the 3D model. Each level of storm is represented in a single rule file developed in CityEngine. All geometry, imported models, and textures are included in a single .cga code and produced scene. Assets such as trees and other elements of the city that would suffer damage from a hurricane are imported into the scenes. This process is repeated for each category of a hurricane, Category 1 through Category 5.

The following bullets illustrate the process of .cga script development:

- Read Saffir-Simpson hurricane category descriptions

- Investigate photos of damage from each storm category

- $\quad$ Build 3D models with //<Lot $\rightarrow$ extrude (heightvalue) $>/ /$

- Put a roof and façade on the models with $/ /<$ resRoof $\rightarrow$ roofGable $(30,1)>/ /$, and $/ /<$ resFacade $>/ /$

- Texture model surfaces with //< texture (.jpg/.tif) $>/ /$ and $/ /<$ project UV (0)>//

- Manipulate geometry of models scope with $/ /<\mathrm{r}(\mathrm{x}, \mathrm{y}, \mathrm{z})>/ /$ and $/ /<\mathrm{t}(\mathrm{x}, \mathrm{y}, \mathrm{z})>/ /$

- Coordinate geometric manipulation with //<attr offset_damage>// 
- Parameterize visual effect of .cga script by changing constants in each operation i.e. $/ /<r\left(1.5^{*}\right.$ offset_damage, $1 *$ offset_damage, $2 *$ offset_damage $)>/ /$

- As offset_damage slider is moved from lower values to higher values damage appears worse, debris becomes visible, textures change

- Create and texture flood surface and coordinate with damage levels $/ /<$ extrude (value*offset_damage) $>/ /$

The first step in 'destroying' a scene according to a specified level of storm damage is to build the 3D components of a scene that represent an area in the path of a potentially catastrophic weather event. 3D models of post-hurricane damage are generated through a process of recursive destruction such that the scene represents an area hypothetically impacted by a storm. 3D elements of the built scene environment thus signify the likely extent of damage to occur from a storm event with the intent of communicating to the general public the storm risk and potential damage.

The next step is to extrude 3D objects from the building footprints using a rule in .cga code $/ /<$ Lot $\rightarrow$ extrude (value in meters) $>/ /$. The 3D object is extruded to a height value set by the .cga code or the .cga code can query a list of attributes in the building shapefile to construct the building model according to the recorded building height. Standard elements of the building architecture are created in the lines of code $/ /<$ comp (f) \{top: resRoof | side: resFacade | bottom: resFloor $3>/ /$. These codes take recognized elements of .cga and give them names. The 3D geometric features of the extruded polygon are the first part of the code. These are building elements already embedded in .cga shape grammar //<top:, side:, bottom:>//. The names of shape rules are the second element that follows the colon, $/ /<$ resRoof, resFacade, resFloor $>/ /$. The shape of the roof is determined by an angle where the sections of the roof meet. The exterior walls of a structure are assigned a given size specification based on the dimensions of the building footprint and the building's extruded height. In the 
case of these models, because the intent is to show destruction, the building is extruded to a height based on a variable whose value represents damage to the building - called //<attr offset_damage >//. This value is used in multiple parts of the .cga code to alter the appearance of the building models and to depict associated levels of destruction. In this case, an attribute "building height", is set to a random value of between three and five meters. This specification is associated with each building footprint and as damage increases so the height of the building decreases to demonstrate structural damage.

Translating the Saffir-Simpson Hurricane Wind Scale damage descriptions and photographs of storm damage into a .cga rule file in CityEngine presented numerous challenges. The .cga script developed for this research allows a user to progressively increase scene damage based on a userspecified value. However, parameterization of this value proved to be time consuming and rife with challenges. Setting these values was eventually achieved by building an attribute called $/ /<a t t r$ offset_damage $>/ /$. This attribute was a preset, user created attribute value, known in CityEngine as a handle. By creating a range of appropriate values for the $/ /<$ attr offset_damage $>/ /$ handle, the .cga rule initiates changes to the geometric structure of the model in CityEngine and depicts the related storm damage (see code sample in Figure 3.11). The degree of storm damage is achieved by setting damage values as a coefficient of the geometric features in the building's scope and in the scope of objects tied to parts of the building. The debris created from the destruction of objects in the built environment is tied to the //<attr offset_damage>// value. As a result, higher values of the //<attr offset_damage>// attribute translates to the dispersal of debris throughout the scene, a greater rotation of building features such as walls and roofs, as well as a decrease in building height related to the buckling of support walls under high wind speeds. Textural elements in the models were also affected by an increase in damage value such that as a building begins to "fall apart" in the CityEngine scene, so the surface textures and roof textures reflect corresponding changes in the building geometry and in the depiction of damage. 


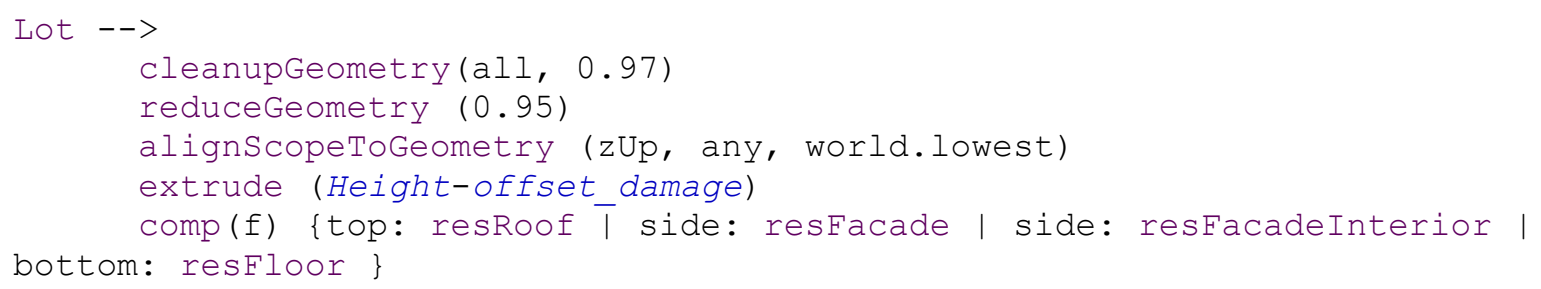

Figure 3.11 - Basic building geometry .cga code, @StartRule for HurricaneDamage, Source: author screenshot 2017 


\section{Chapter 4 - CityEngine, Computer Generated Architecture, and hurricane storm damage}

A CityEngine scene, then, is comprised of images, maps, assets, models and a rule file of procedural .cga code and an intended programming goal. This research utilized and adapted the (socalled) Simple Procedural Destruction .cga code to create and depict the destruction of 3D building models (Figures 4.1 and 4.2). The .cga code was developed to recognize specific elements of the 3D model polygons that were developed in a CityEngine scene representing the built environment of a neighborhood. The spatially referenced building footprints and extruded 3D objects are accessed within the .cga rule file and procedural destruction is then undertaken to systematically 'destroy' specific elements of the scene. The degree of destruction is undertaken according to precise specifications of the descriptors used to define the various stages and severity of hurricane damage. The extent and degree of damage applied within a CityEngine scene is user-specified within the cga code according to the predicted severity of the hurricane. The levels of damage captured in the procedural rules for each specific hurricane category can be applied to any CityEngine scene to indicate the extent and nature of potential damage predicted for that neighborhood under differing stages of hurricane severity. Thus rotating, translating, and modifying the polygon geometry of each building model or feature model along with concomitant changes in the image texture polygons and the introduction of 3D debris models is undertaken and the results displayed (See Figures 4.3 and 4.5 ).

One of the most powerful components of CityEngine is the ability to incorporate attribute datasets. Information in an attribute format attached to discrete polygons in a shapefile can be used to identify and analyze specific characteristics of each building in the scene. This enables CityEngine to potentially incorporate tax parcel data, building values, and zoning codes. It is of particular interest to this research that emergency managers can estimate losses and risk areas in the event of a potential 
storm while maintaining a product that can be used in times of real emergencies. The applications of CityEngine to be a tool for communicating critical socio-statistical information within a visual framework are manifold and are further discussed in the following chapter. In building the 3D components of a scene representing an area in the path of a potentially catastrophic weather event the model must be responsive to the five stages of the Saffir-Simpson Hurricane Wind Scale. Based on these five hurricane stages, 3D models of post-hurricane damage illustrate the related extent of storm damage to those neighborhoods. Two possible programming procedures were identified using CityEngine 3D models and .cga code to accomplish the goal of depicting the impact of a hurricane on neighborhoods. The first and perhaps least technically problematic was to use a discrete approach and to separately model each hurricane stage. Such a discrete approach would create specific assets and models within a scene which would then be destroyed to a specific hurricane storm damage level such as Hurricane stage 1 . This process would then be duplicated as a separate stand-alone process for each of the remaining hurricane stages. Each depicted level of damage would be saved as a separate scene file and would require display and interrogation independent of all other scenes, not only is this a less elegant solution but it would raise difficulties in accurately reproducing scenes and in optimizing system performance. Reproducibility is an important part of this study, because a damage value or hurricane category must be consistently represented in order for the trust of the general public to be maintained in their interpretation and evaluation of the model.

The second option that was identified was to pursue an integrated approach through a custom procedural rule file in CityEngine that would depict damage within a particular scene for all hurricane severity stages by progressively manipulating geometry according to which hurricane level was specified in the .cga code. This approach was pursued in this research and was achieved by creating one .cga rule file that was made capable of progressively changing attributes and model elements according to the level of destruction specified in the code. The single .cga rule file and scene embedded destruction levels 
that correspond to the geometrical and textural manipulations of the 3D objects in the scene. The primary mechanism used to achieve the depiction of damage is predominantly based on changing the building height along with the manipulation of roofs and wall geometries. Damage to roof surfaces, house siding, and other building materials are symbolized by changing that polygon's texture with an image that represents storm related deterioration in the façade such as the use of plywood or other base materials. Damaged trees, vegetation and above ground infrastructure are obvious clues that an area has been impacted by a recent catastrophic event. Trees are progressively changed in height to create the effect of trees falling and combining with other debris. If a higher polygon count could be sustained by the system then street furniture and urban infrastructure such as tree limbs, cars, furniture and the like would be seen strewn across roadways and sidewalks. Additionally, the surface images in the model are made to change as damage escalates from superficial external building damage to significant structural damage to building components and major features of the built environment. As hurricane magnitude and damage increases, so there is related greater damage recorded to the buildings. Each hurricane storm magnitude category is broken down in terms of the characteristic damage and then subsequently modeled based on the descriptions provided in the Saffir-Simpson Hurricane Wind Scale and comparison to photographic evidence (Saffir-Simpson 2012).

As part of the Simple Procedural Destruction cga code, two types of damage are deployed RandomDestruction and DirectedDestruction (Figure 4.2). Both destruction types refer to specific geometric operations that change the polygonal geometry of an object shape according the scope of the elements which make up the shape. 


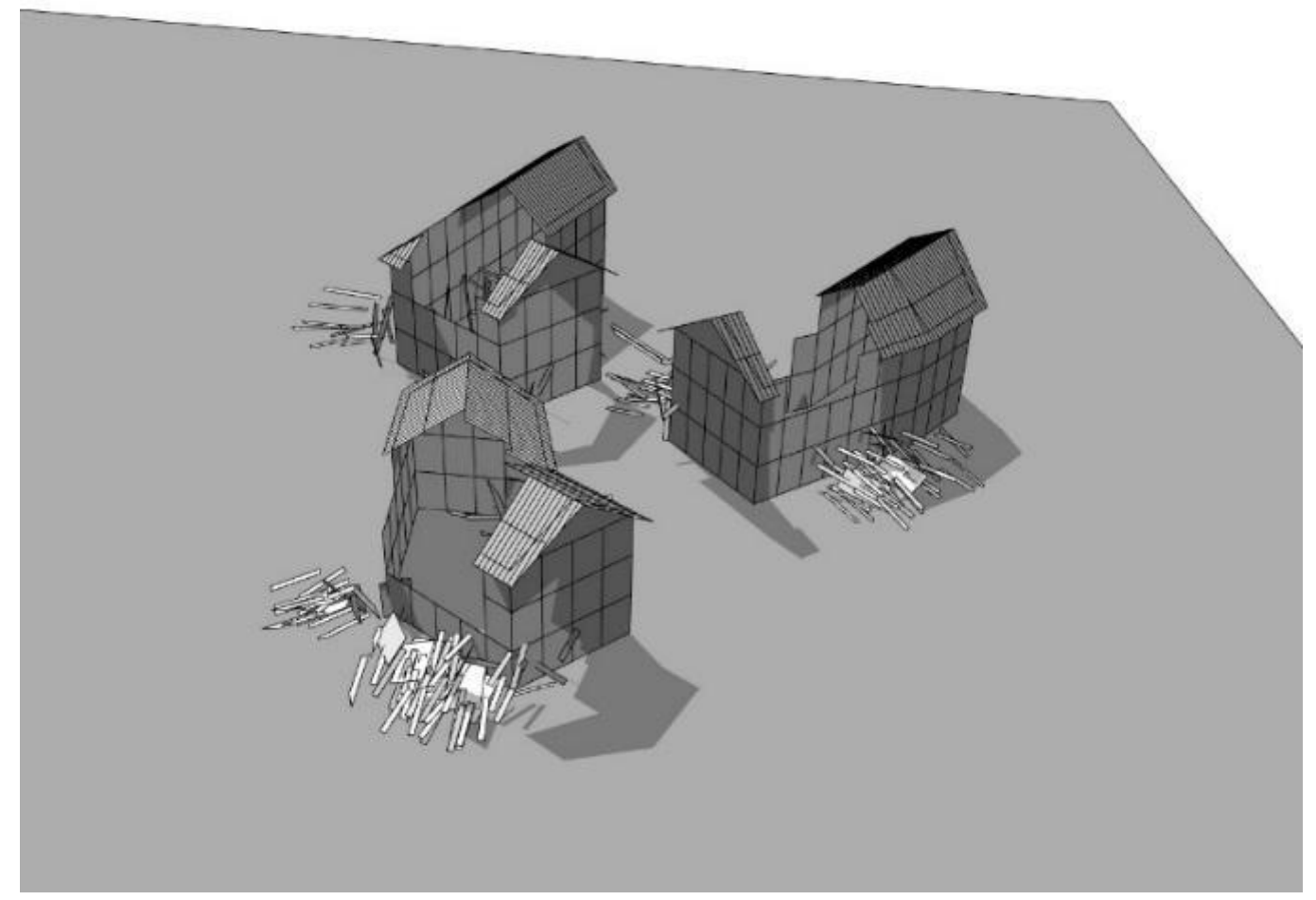

Figure 4.1 - Example simple procedural destruction of home buildings. Source: Simple Procedural Destruction, https://geonet.esri.com/externallink.jspa?url=http\%3A\%2F\%2Fforums.esri.com\%2FCityEngine\%2Fforum-17845.html 


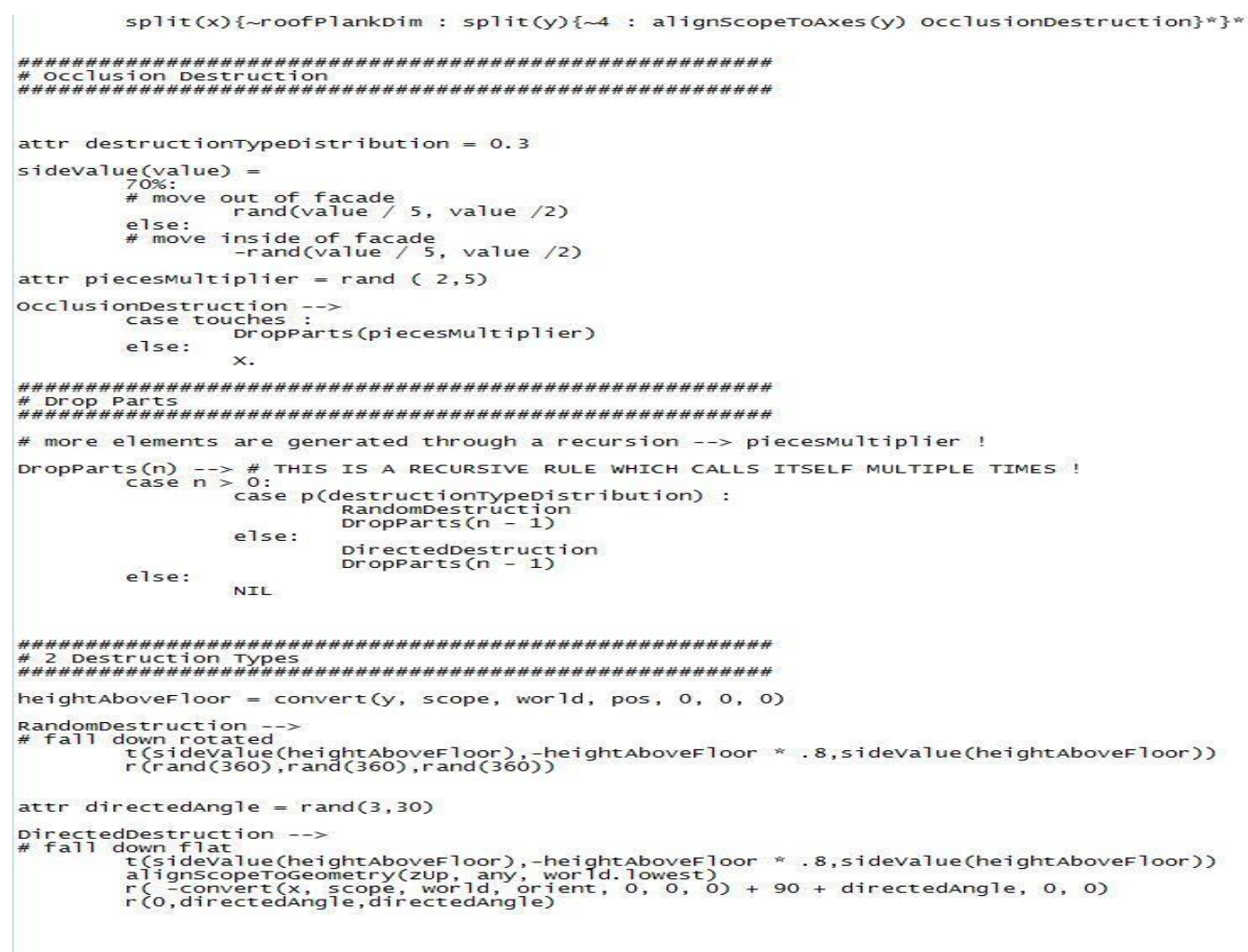

Figure 4.2 - Screenshot of "simple" procedural destruction .cga code. Source: Simple Procedural Destruction, https://geonet.esri.com/externallink.jspa?url=http\%3A\%2F\%2Fforums.esri.com\%2FCityEngine\%2Fforum-17845.html

The Simple Procedural Destruction .cga code was adapted in several ways for utilization in this project. The first and most obvious visible difference between the Simple Procedural Destruction and the changes made to the code for this study is the lack of textures in the screenshot of Simple Procedural Destruction (Figure 4.1). The original author of the Simple Procedural Destruction created this code as a proof of concept to show how video game developers might use procedural models to depict massive damage within a gaming environment. In contrast the hurricane damage .cga code was designed to communicate with a group of people who might potentially be in the path of a storm, and to depict various damage scenarios to these groups in a local context. As a result, detailed elements of the scene such as building textures and trees are included to provide local context in the visualization. To provide local context, an element of the workflow is dedicated to collecting and then creating 
building façades and roof textures according to the locale in which the event is purported to be taking place.

The most challenging modeling element to manipulate in the depiction of damage was with regard to the roofs of the residential buildings. The cga code contains geometry subdivision operations that allow a user to split across an $\mathrm{x}$ or $\mathrm{y}$ axis and to take one polygon and turn it into two or more pieces. This split operation is especially effective for creating parts of buildings such as doors, windows, and features of architectural design which can then subsequently be decomposed to represent damage to the structure. The CityEngine program experiences difficulties drawing roof items when a roof is applied with a split operation, and the roof generally stays in one piece and is erroneously displayed in the model. Instead of breaking into split pieces like facades, the roof has to be geometrically manipulated using a rotate operator. The rotate operation turns the roof to show the effects of wind on the roof gable ends. This process also depicts the separation of exterior support walls from the roof area. The roof scope rotates and depicts the disconnection of roof gables from the exterior walls of the home. This roof rotation can be seen in many post-storm damage photo surveys and galleries available from the news media and government organizations. The $/ /<$ resRoof $>/ /$ rule is also represented with a photo texture of shingles or bare plywood in the case of higher damage levels. The roof textures are a collection of what appear to be shingles and other materials used to cover the base roof decking. The Saffir-Simpson scale repeatedly mentions roof elements as a means of communicating the potential impacts from storm damage and as a result this study has focused heavily on manipulating roofs as a means of communication the extent of structural damage to buildings (Figure 4.5). 


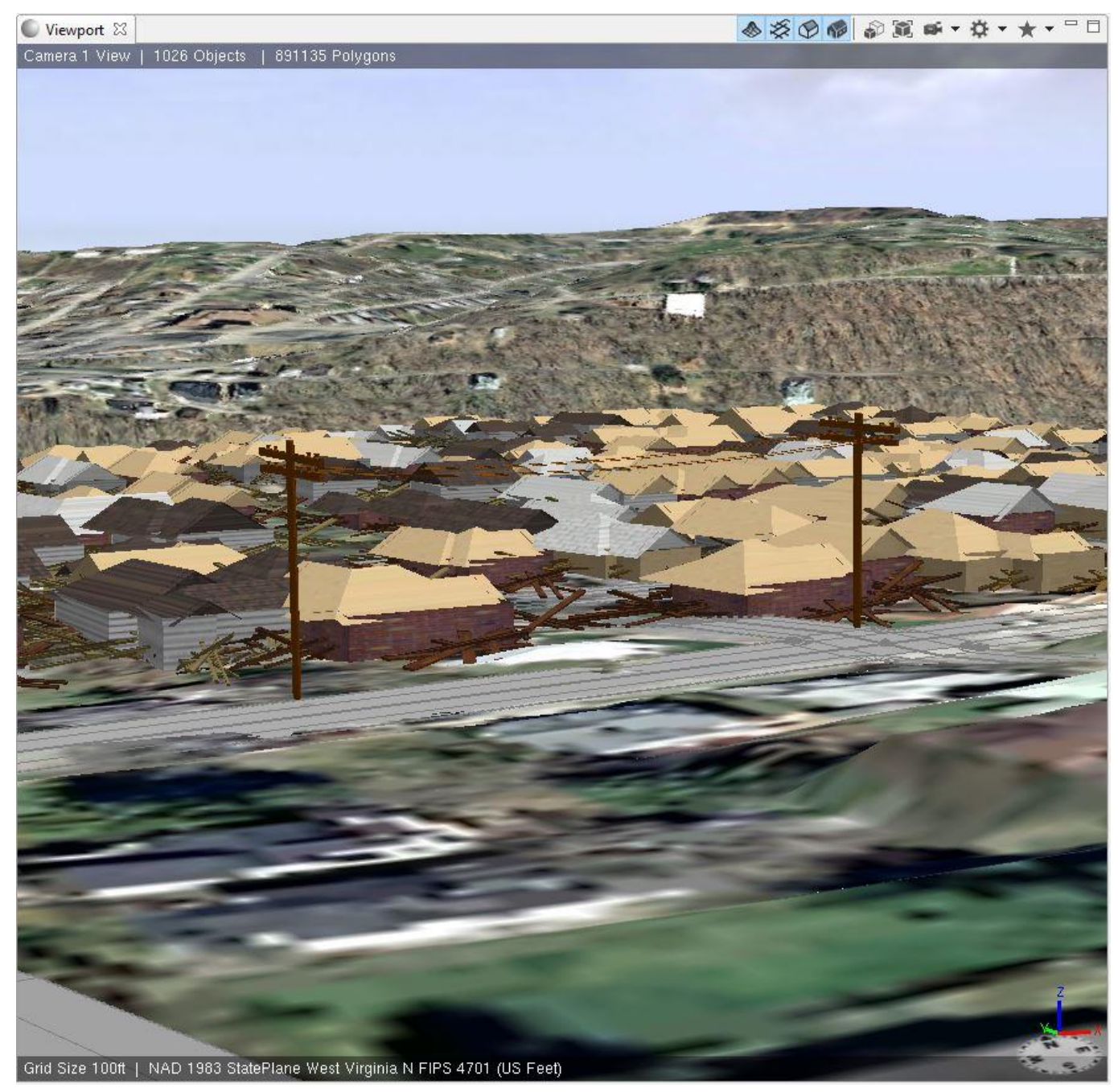

Figure 4.3 - Utility pole and debris pile models aside .cga created shapes in CityEngine scene Source: author screen capture, 2017.

Perhaps one of the single most important functions provided within CityEngine is that of the scope (Figure 4.4). Scope is a term used in CityEngine to describe the 3D orientation bounding box that is used to apply geometric changes to objects at a specific scale or direction. The direction of the scope elements in the shape can be set using the alignScopeToGeometry operation so that the y or z scope vector can be set to $y \cup p$ or $z U p$. The scope of a shape in CityEngine is subject to three vectors that 
change the model geometry according to a specific attribute or other defined value. The three scope vectors are translation, rotation, and size. Both translation and rotation are used extensively here in this study to depict changes in roof orientation resulting from the degree of damage specified and to move debris from its original location to various places around the scene indicative of storm damage.

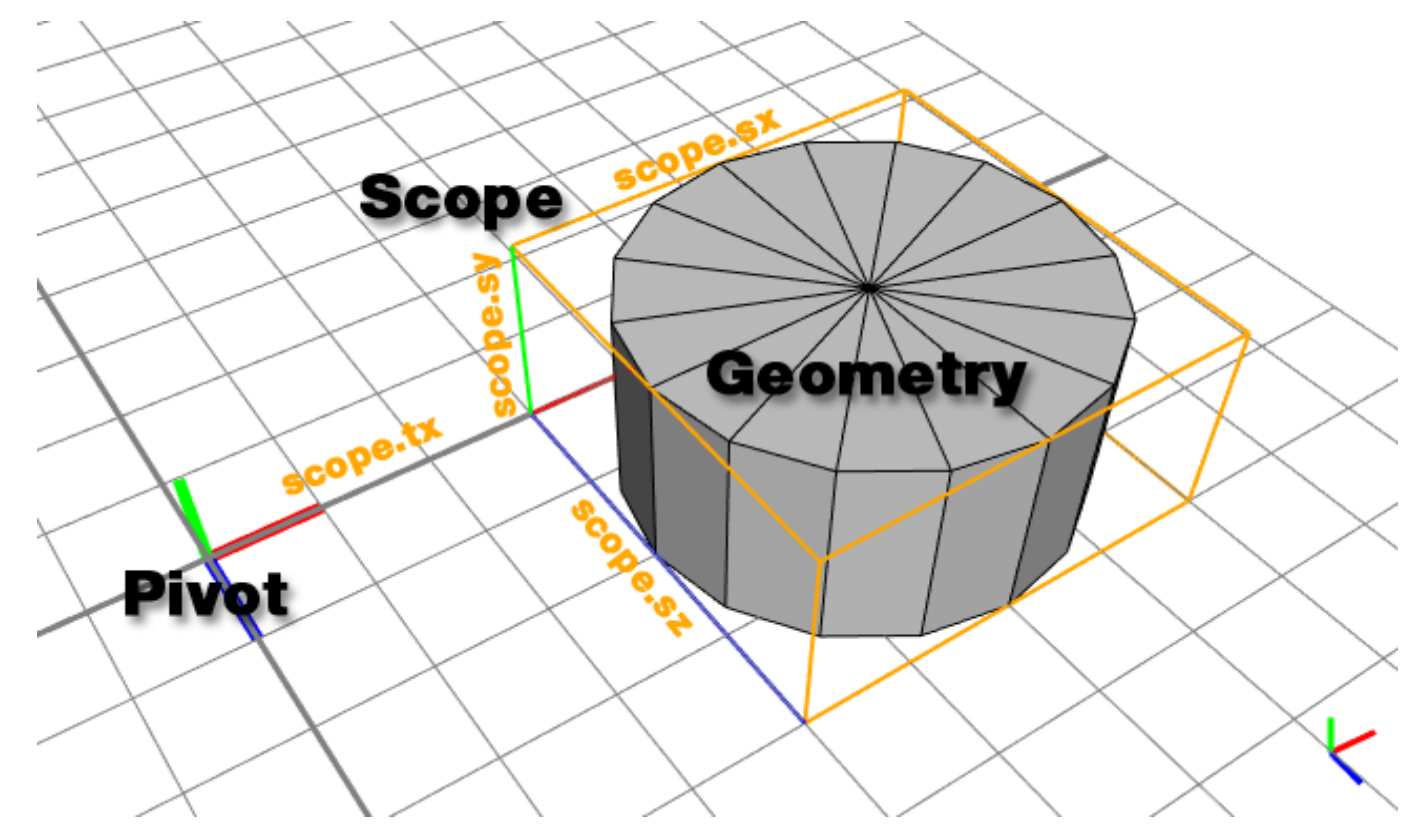

Figure 4.4 - CityEngine Scope, Pivot and Geometry Source: CityEngine Help, http://cehelp.esri.com/help/index.jsp?topic=/com.procedural.cityengine.help/html/cgareferenc e/attr_scope.html

In photos and descriptions of hurricane damage an emphasis is placed on the destruction of exterior walls. Exterior walls are extruded in relation to the buildings' extruded heights. To visually depict damage in a manner similar to real world hurricane impacts, building walls would need to be geometrically constructed of models that more realistically represent real world componentry such as 2"x4" rectangular cylinders textured with wood grain photos as support pieces; flat rectangles textured to appear as plywood; drywall rectangles; and so on. Building height is changed in the rule set in accordance with projected storm damage. While building heights are extruded to a value of between 
three and five meters, this height is changed as a consequence of an increased damage value. This a reduction in height allows the scene to progressively display the destruction of features and somewhatrealistically show damage levels of progressively more destructive hurricanes while avoiding the difficulties of displaying a scene with greater than 100 million textured polygons. The cleanupGeometry function was used to remove duplicate geometry from extruded features. Values of between 0 and 1 are accepted and decimal values correspond to percent cleanupGeometry; a value of 0.97 reduces the polygon count by 97 percent of the geometric features in the dataset.

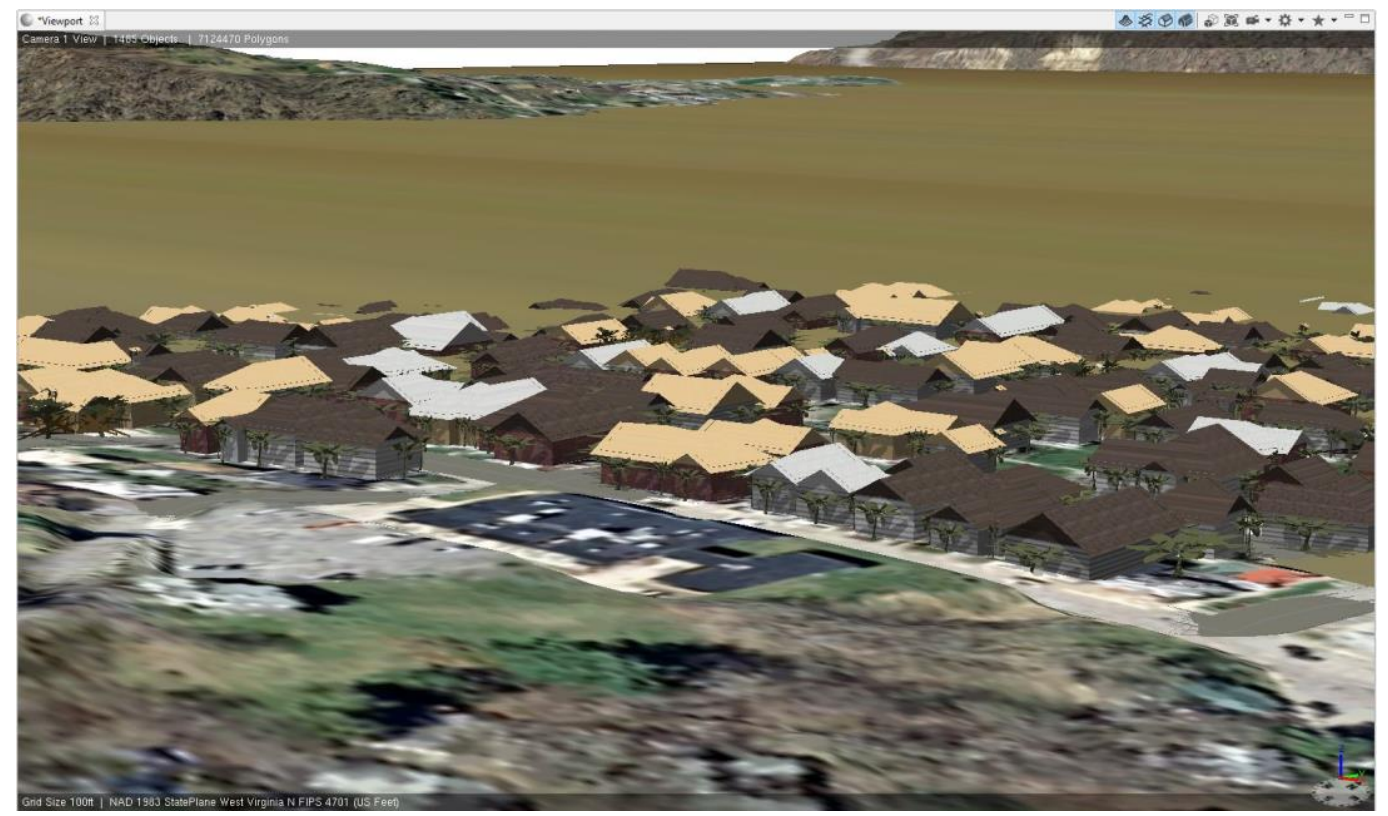

Figure 4.5 - Category 1, offset_damage 1, Flood 6 Source: author screenshot, 2017

Debris is also affected by the damage values set in the .cga code to show the most debris at the highest hurricane category (5) and the least debris at the lowest category hurricane (1). The debris parameter is set in the .cga code to distribute 30 objects in a standard distribution across the surface of the building facades and landscape creating a visual effect that makes the buildings appear to be damaged on both the interior and exterior façade surfaces. Debris increases with changes made to the 
$/ /<$ attr offset_damage $>/ /$. As the damage value progressively increases, so roof pieces also rotate in relation to //< attr offset_damage $>/ /$. When the roof pieces rotate, at near Category 3 damage levels, the debris can be seen both inside and outside of the building facades to reflect comprehensive damage inflicted by the storm.

For each of the Saffir-Simpson stages a parameter setting sought to replicate similar levels of damage commensurate with the description.

\section{A Category 1 hurricane scene}

74-95 mph 1-minute average sustained winds. Very dangerous winds will produce some damage: Well-constructed frame homes could have damage to roof, shingles, vinyl siding and gutters. Large branches of trees will snap and shallowly rooted trees may be toppled. Extensive damage to power lines and poles likely will result in power outages that could last a few to several days (Saffir-Simpson 2013).

The parametrization routine involved a series of changes to the cga code, observation of the modeled changes, and verification from text and photo evidence of storm damage. In short, if the .cga code did not produce a scene that fit the photos and the Saffir-Simpson descriptions, then the information was returned to the .cga code and rotation, translation, scale were changed accordingly. In one case, as the height of the façade decreased and trees became attached to the façade, the tree model was "squished" and was made to appear with a wider canopy. This effect was parameterized using the scale operation. By setting the scope axes to $/ /<\mathrm{s}(0.011 *$ offset_damage, $0.021 *$ offset_damage, $0 *$ offset_damage $)>/ /$ the scale of the $x$-axis of the tree model changes according to damage, in this case, $11 / 1000$ multiplied by the $/ /<$ offset_damage $>/ /$ value makes the tree appear at a more appropriate scale. The same parameterization routine was performed on roof, façade, and building height extrusion to create a 3D visualization that appears as real as possible. 


\section{A Category 2 hurricane scene}

96-110 mph 1-minute average sustained winds. Extremely dangerous winds will cause extensive damage: Well-constructed frame homes could sustain major roof and siding damage. Many shallowly rooted trees will be snapped or uprooted and block numerous roads. Near-total power loss is expected with outages that could last from several days to weeks (Saffir-Simpson 2013).

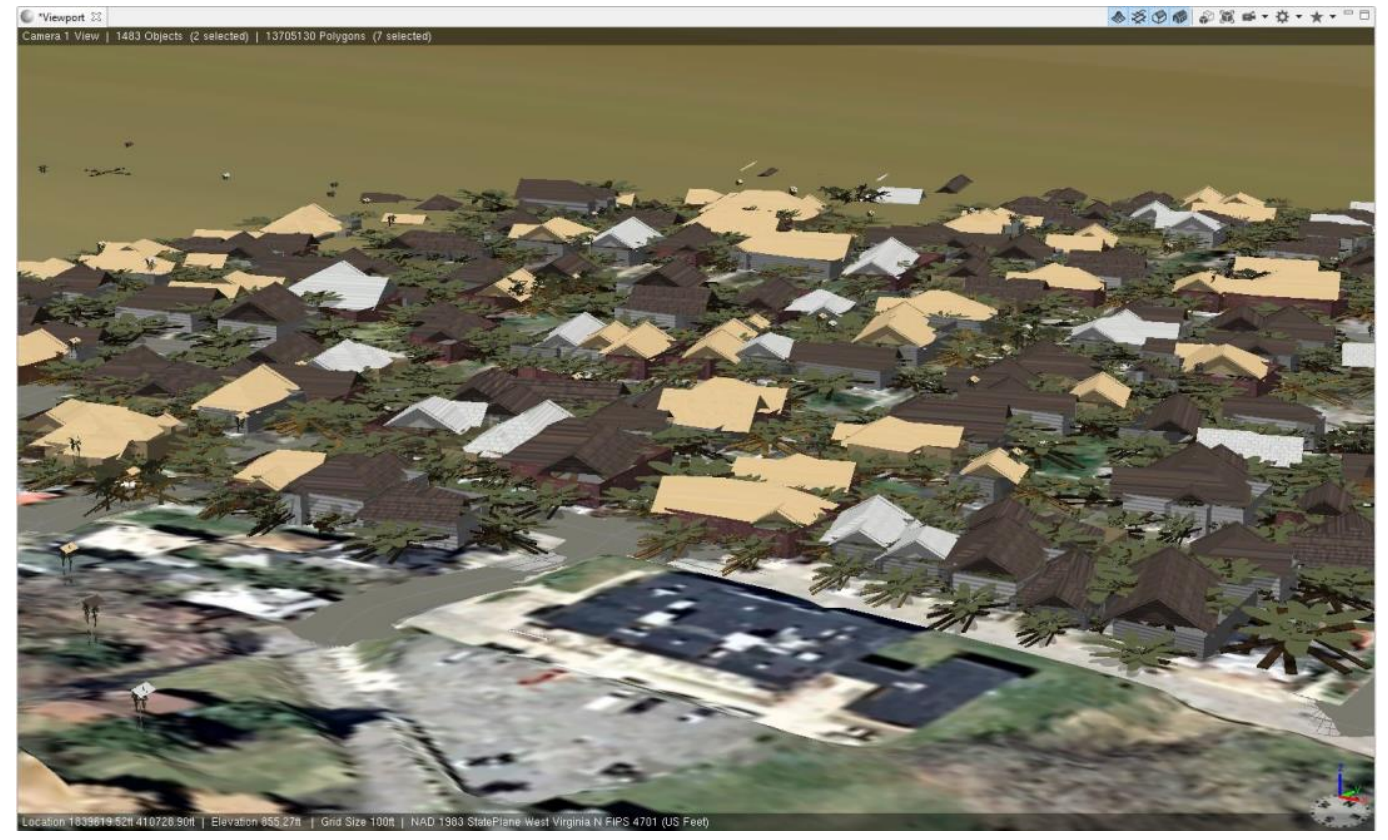

Figure 4.6 - Category 2, offset_damage 2.6, Flood 6, Source: author screenshot 2017

The .cga code was adapted to incorporate "major roof and siding damage" by rotating roof

pieces and walls (see Figures 4.7 and 4.8). A sample rotation .cga script followed a rule signified by

$/ /<$ RuleName - $->/ /$, and the rotation is initiated as follows $/ /<r(x, y, z)>/ /$. The rotation used for

hurricanedamage.cga embeds a variable damage value and multiplies the damage value by a constant in

the rotation command. The constant in the rotation command, shown below as "\#" was parameterized according to the Saffir-Simpson text descriptions aided by photos of past storm damage. The following code is used to create visual depictions of damage via rotation in the CityEngine scene: 
$/ /<$ r(\#* offset_damage,\#*offset_damage, \#*offset_damage) $>/ /$, where $r$ initiates rotation of the scope and a user defined constant value is parameterized for each direction of the scope $x, y$, and $z$.

Previous storms with Category 2 classification have completely removed shingles from damaged roofs, and decking and siding are seen to be torn from houses. In order to create this in a 3D scene, the models were textured with photos that symbolized sections of roof that are reduced to structural and interior features instead of exterior shingles.

\section{A Category 3 hurricane scene}

111-129 mph 1-minute average sustained winds. Devastating damage will occur: Well-built framed homes may incur major damage or removal of roof decking and gable ends. Many trees will be snapped or uprooted, blocking numerous roads. Electricity and water will be unavailable for several days to weeks after the storm passes (Saffir-Simpson 2013).

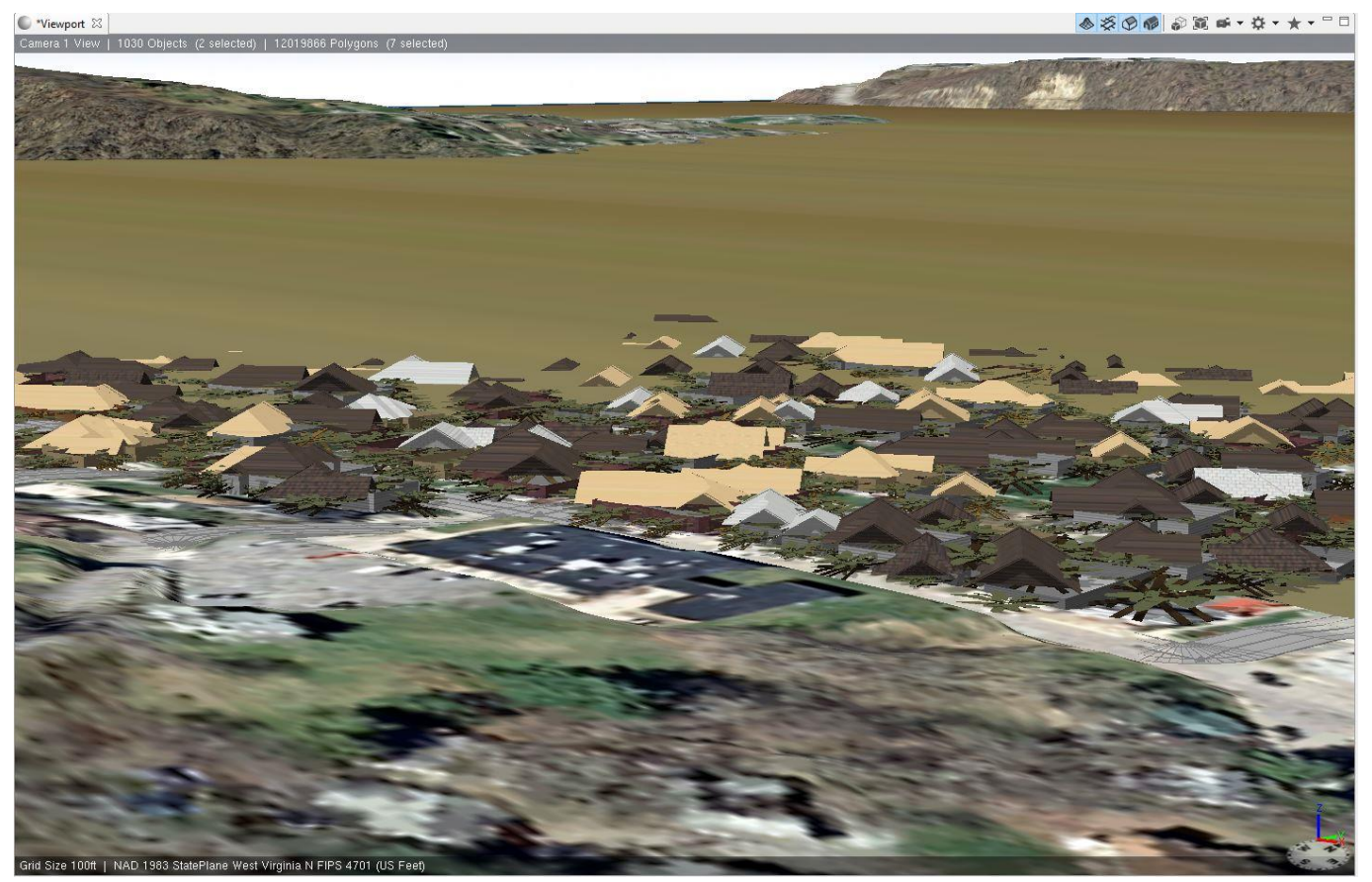

Figure 4.7 - Category 3, offset_damage 5.6, Flood 8, Source: author screenshot 2017

Damaged trees are displayed throughout the scene in association with exposed building

foundations; damage to building facades; and roof materials are depicted as totally destroyed and 
distributed throughout the area as pieces of the roof continue to rotate under the force of greater than $100 \mathrm{mph}$ winds. Buildings will be seen to be progressively diminished and debris is more liberally strewn across the ground. The space between houses is more densely filled with debris associated with a major hurricane event.

\section{A Category 4 hurricane scene}

130-156 mph 1-minute average sustained winds. Catastrophic damage will occur: Well-built framed homes can sustain severe damage with loss of most of the roof structure and/or some exterior walls. Most trees will be snapped or uprooted and power poles downed. Fallen trees and power poles will isolate residential areas. Power outages will last weeks to possibly months. Most of the area will be uninhabitable for weeks or months (Saffir-Simpson 2013).

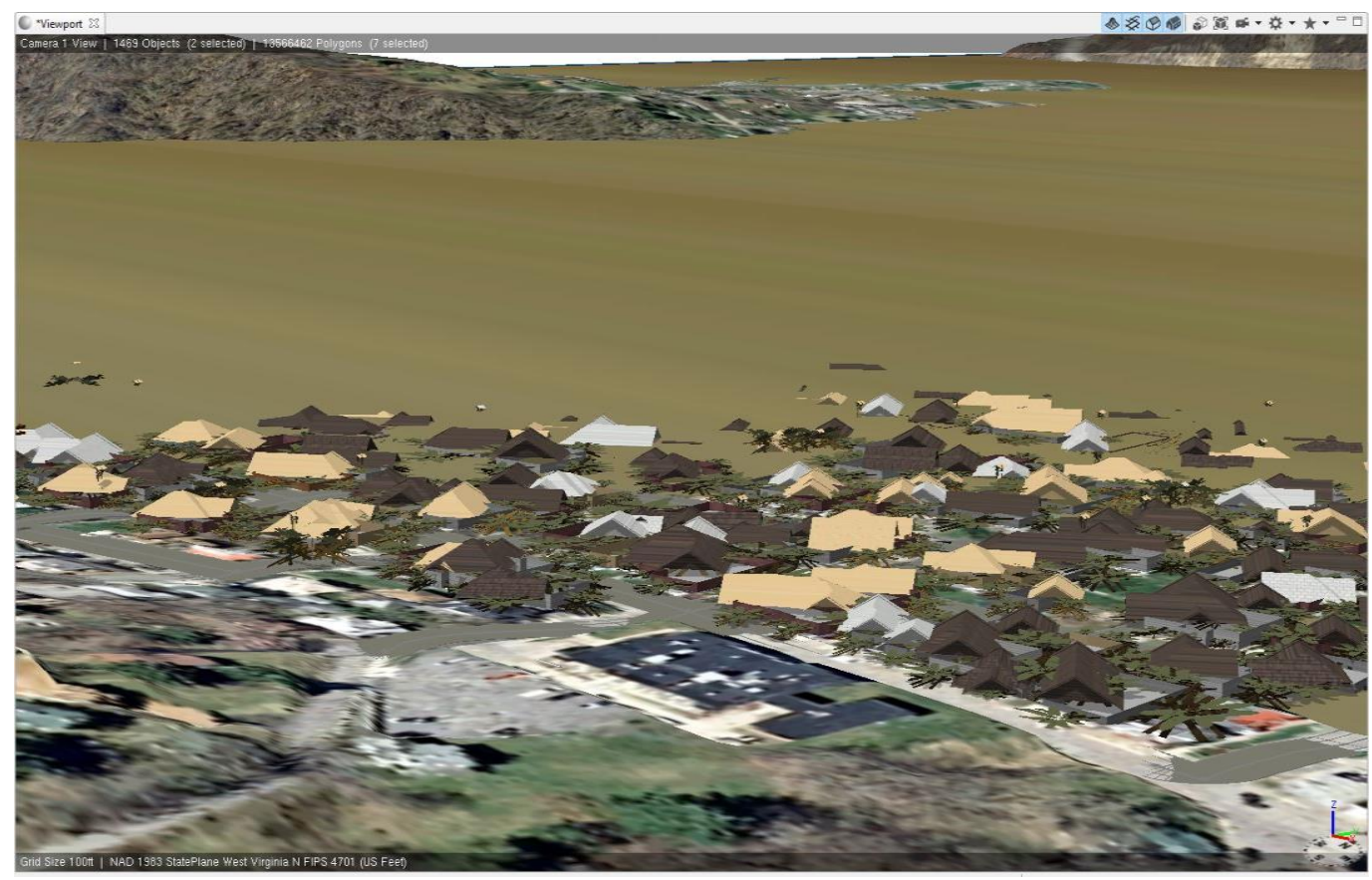

Figure 4.8 - Category 4, offset_damage 6, Flood 10, Source: author screenshot 2017

At this level of destruction, the buildings walls are severely damaged and in some cases have collapsed and the walls are rotated on their foundation. Trees are snapped, uprooted and otherwise 
demonstrate severe damage. The scene takes on a truly catastrophic tone as if the object contents have been put in a blender and redistributed, lacking any recognizable features. This visualization also assumes major flooding will occur and many houses will appear to be inundated.

\section{A Category 5 hurricane scene}

157 mph or higher 1-minute average sustained winds. Catastrophic damage will occur: A high percentage of framed homes will be destroyed, with total roof failure and wall collapse. Fallen trees and power poles will isolate residential areas. Power outages will last for weeks to possibly months. Most of the area will be uninhabitable for weeks or months (Saffir-Simpson 2013).

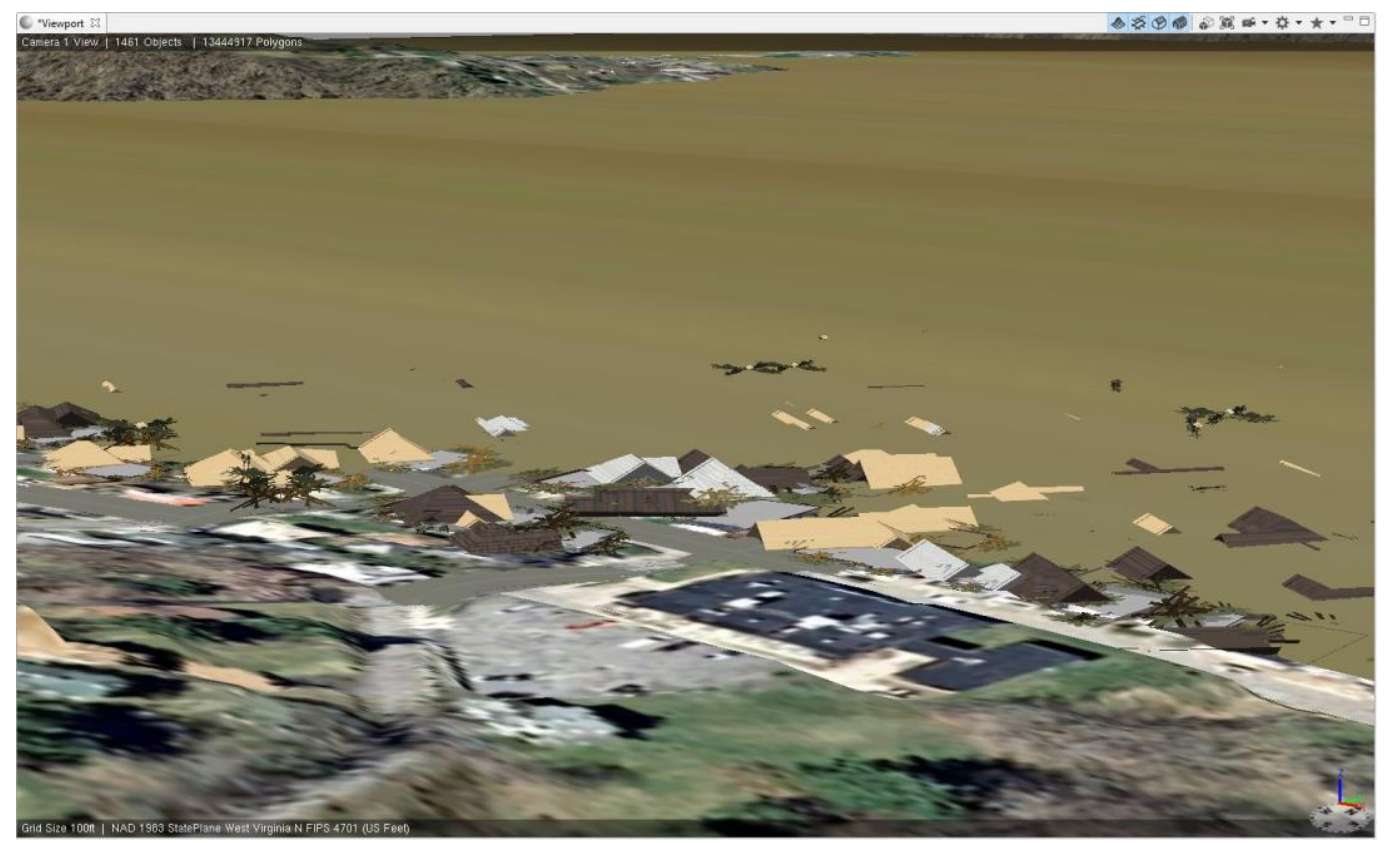

Figure 4.9 - Category 5, offset_damage 8, Flood 11, Source: author screenshot 2017

Under a category 5 designation essentially all houses and buildings will be completely demolished and destroyed. Building foundations will remain, but all structures above the surface will be annihilated and very few structural objects will remain, even partially intact. This level of damage is displayed in the 
scene by reducing the height of building structures to near ground-level and unrecognizable pieces of roofs are scattered liberally across the area. Flood waters will severely inundate almost the entire scene.

As demonstrated above, CityEngine is able to accommodate both the creation and display of hurricane damage at a neighborhood scale. The most challenging part of displaying damage in the scene arose from the parameterization of the damage value. However, once calibrated the visual representations of the potential impacts from hurricane damage provide valuable information and motivation for people to take action. As the suite of applications expand so that this information will be available on mobile devices such information will become more accessible and ubiquitous. 


\section{Chapter 5 - Evaluation and Discussion}

Considerable efforts have been made to recognize weather communication products as part of the process of communicating severe weather event warnings to the public (Gladwin et al. 2009, Demuth et al. 2012). Hurricane forecasting and prediction forms a boundary object between expert opinion and the general public perception of risk. The research presented here suggests that geovisualization of these storm events represents a more intuitive and powerful representation to communities, and indeed to experts, rather than more traditional forms of communication alone. At the outset this research sought to pursue and achieve several critical questions and objectives:

$\checkmark$ Create a 3D scene in CityEngine.

$\checkmark$ Depict 3D building, terrain, and urban infrastructure in a CityEngine scene

$\checkmark$ Develop an integrated system of procedural rules to progressively destroy buildings

$\checkmark$ Create building and infrastructure objects and textures that help represent damage within the 3D neighborhood scene

$\checkmark$ Create five separate Saffir-Simpson geovisualizations of hurricane damage.

$\checkmark$ Seek some initial feedback

A formal survey of this research lies beyond the resources of this project and yet the next stage in the work would be to seek such feedback. However, as part of a class exercise in representation and geovisualization some feedback and discussion was obtained. In addition, informal viewings and feedback from fellow peers, colleagues, friends, and some faculty members as I displayed my work has 
also provided a modicum of feedback on the work. In these discussions and in the class project the several forms of hurricane warning and risk were communicated including category and wind speed (hurricane category descriptions in chapter 4), hurricane track map (Figure 1.2), satellite hurricane photo (element of dashboard in Figure 5.1), actual photographs of the hurricane impact on buildings (Figure 3.6), and 3D visualizations arising from this project (Figure 4.9).

This informal feedback was valuable in reinforcing some of the issues laid out in previous chapters and in providing anecdotal support for the use of 3D visualizations. What was not expected was how many thought that a combination of some of the communication mechanisms actually provided a stronger means of representing hurricane information than just a single representative form. Thus feedback on the Saffir-Simpson Wind Scale alone was somewhat negative in terms of its ability to communicate hurricane risk and to influence perception of potential damage to property and lives arising from such an event. Comments such as 'The category of wind speed only gave you information about the type of hurricane, not about the potential risks besides the fact that the wind speeds are fast' gave a window into the perception of the people who use the different hurricane communication products. A close second was the hurricane track map which many commented gave an indication of the direction and track of the storm but not its severity or potential impact. The latter point about assessing the magnitude of the storm was addressed somewhat by the hurricane satellite map which indicated the spatial extent but again did not provide sufficient information concerning potential damage impact.

In contrast to these representations, the photographs and 3D visualization were highly rated in terms of their ability to communicate the potential damage that could occur from the storm. As one student commented, "The photos and visualization helped me relate the actual damage these storms can cause. Someone with an untrained eye may have trouble understanding how powerful these storms 
are with numbers and satellite photos". Several referred in their comments to the ability to gain an understanding of the potential impact of the storm based on the scene representing a local neighborhood: "The 3D visualization of an area where a personal community or neighborhood is the focus would have the strongest impact on me. Seeing your neighborhood, house, or city under water or destroyed would make me evacuate based on the storm severity". Or as another commented, "3D visualization was the best way to actually visualize the impact and understand what you may experience." Several commented on the powerful combination of both the 3D visualizations and the actual real world photographs, "The photos and 3D visualization helped me assess potential risk more than the other categories. A number or value can only have so much of an impact but a picture and the 3D visualization show true results/possibilities of the potential risk".

One specific comment was particularly helpful in thinking of future research directions: "I would consider a combo of wind speed, satellite image, and damage photos to be the best for relaying the severity of a hurricane - they are more intuitive perhaps". This feedback was particularly insightful. As a result perhaps future research should think less about solitary, stand-alone representations, and more in terms of a combination of representations. Thus a dashboard approach (Figure 5.1) to hurricane prediction of risk assessment that blends the strengths of several forms of representation is more meaningful for understanding the location, direction, spatial extent, and potential damage to the local community. This is potentially a more effective solution to hurricane prediction and risk assessment than perhaps any one single representation. Not least, such a dashboard bridges the gap between experts and the general public and the dashboard lessens the knowledge disparity of hurricane risk representations as a boundary object.

Additional future research directions are also worthy of note. First, as noted by other weather forecast communication researchers, the ubiquity of weather information tools and graphical 
representations was confirmed in the enthusiastic response from the audience. The role of weather forecasting tools as a boundary object is very evident in the audience responses which trend along two distinct themes. The first theme arising from the responses sought to engage the expert side of the boundary object which the hurricane damage visualization sought to achieve through geovisualization. Some respondents focused on expanding the depth of the expert datasets used to drive the hurricane damage visualization itself by incorporating building-codes into the building footprint attributes to further vary the types of damage that could be displayed in the scene. Survey respondents also focused on how official flood maps can be used as a data input for the development of the visualization and specifically to communicate 'realistic' flood heights from engineering surveys. These types of data inputs would certainly contribute to a more robust expert tool for hurricane damage visualizations.

The second theme to arise from user feedback suggested making the visualization tool into more of a product for communication to a non-expert audience through the 'gamification' of the 3D modeling experience. To 'gamify' something is to take elements of video game play and apply them to other areas such as marketing, communication, and in this instance hurricane disaster awareness. In this case, one audience member suggested a game experience modeled after the popular game "Oregon Trail" called "Hurricane Trail". In "Hurricane Trail" an individual would be presented with scenarios that could occur in the event of a hurricane and would input an address and see the likely scenarios unfold given differing hurricane warning levels. These in-game experiences could significantly help not only in understanding and anticipating the expected consequences of a hurricane as well as encourage engagement in actually paying attention and seeking information about the proposed hurricane event. In this regard people would begin to appreciate the potential nature of the impending damage such as dealing with debris, power outages, flooding, and restricting movement during and immediately following the storm to obtain basic necessities such as medicine, food, and water. However, whether in 
seeking to meet both the needs of both domain experts and those of the general public, the 3D model or dashboard approach falls between two stools is possible and certainly worthy of further investigation.

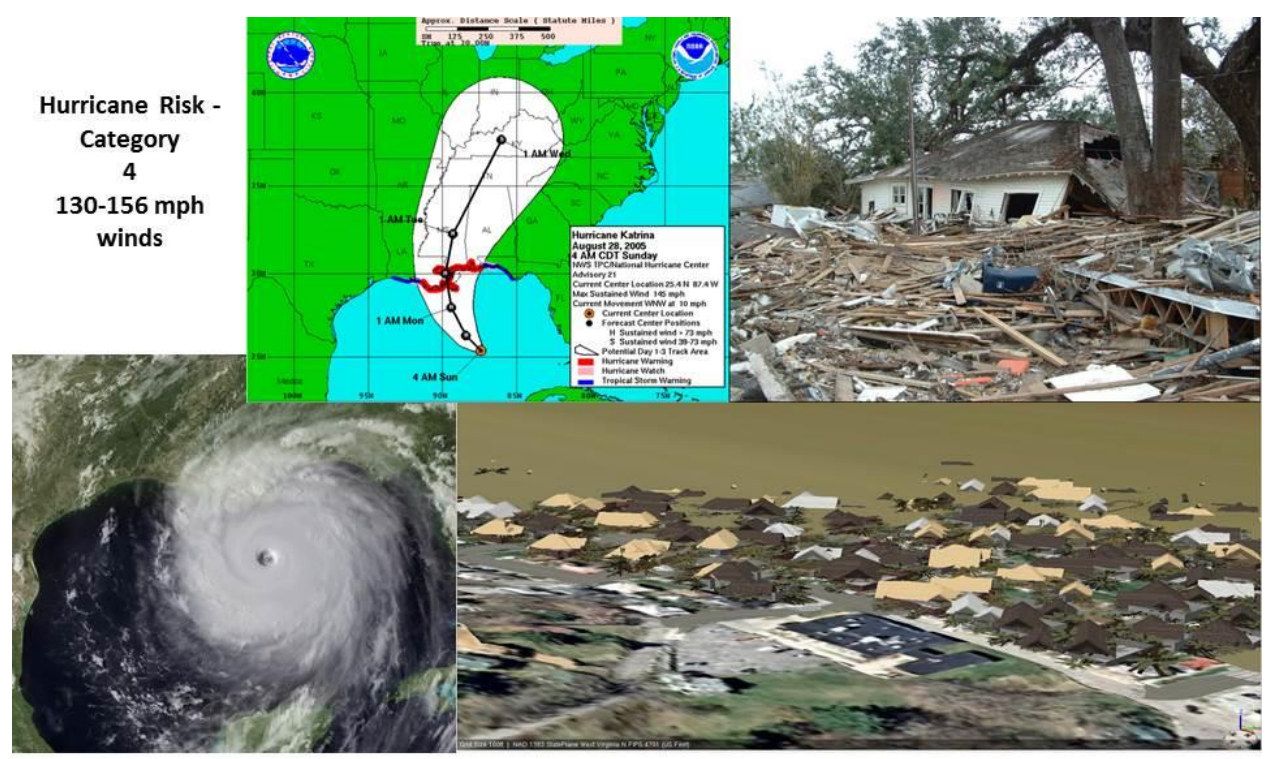

Catastrophic damage will occur: Well-built framed homes can sustain severe damage with loss of most of the roof structure and/or some exterior walls. Most trees will be snapped or uprooted and power poles downed. Fallen trees and power poles will isolate residential areas. Power outages will last weeks to possibly months. Most of the area will be uninhabitable for weeks or months.

Figure 5.1 - Prototype Dashboard approach to communicate hurricane impacts and influence perception of risk

Experience and perception are deeply entangled concepts, especially when considering the perception of one individual versus another. This variability of experience and its influence upon perception adds uncertainty to any interpretation of results because each respondent's level of experience with and perception of extreme weather is unknown. A noteworthy result from the feedback obtained is that the people prioritized information guided by the local context. In fact, one person 
commented that just seeing a hurricane tracking map headed for their location was enough to warrant evacuation. Still others responded in support of the use of 3D GIS visuals, saying that a visual representation of their neighborhood after the impacts of a hurricane would have a significant impact on their perception of risk. This increased perception of risk from hurricane impacts would, they argued, have motivated them to consider taking action to mitigate and avoid the direct impacts of a storm.

Risk communication and improvements in hurricane forecasting products that encourage an understanding and assessment of risk perception would obviously benefit greatly from a better elucidation of the role of human perception and experiences that inform each individual's response to expert information. Most research in this area of extreme hazards risk perception and hurricanes is focused on the structural components of the weather data cycle along with forecast creation and dissemination by individuals whose job it is to mitigate the impacts of weather hazards (Gladwin et al. 2009, Demuth et al. 2012). The pace of technology and the ubiquity of technological products and especially social media technologies and mobile computing in our everyday lives provide numerous opportunities to develop critical approaches to investigating how people act upon information from graphical communication products. In this case the vehicle for delivering these communications was not considered but given the visual dominance of these representations delivery through TV, Internet and mobile devices would be an area worthy of further study. Indeed, the emphasis on the visual was noted by one individual who suggested that an auditory component, whether sound of the storm or a verbal warning or explanation would have reinforced the risk perception still further. In this research, the 3D modeling and perhaps dashboard approach could represent improved forms of warnings and increase risk perception within local communities under threat.

If the transformation of a weather event into a weather disaster hinges on an understanding of risk in the general population, then it can be argued that a more realistic and intuitive representation of 
potential impacts arising from a hurricane is necessary to improve the perception of risk amongst the general public. In short, the longer term goal must be to continue to close the gap between expert information and its receptivity and effectiveness with the general public. This research has sought to translate expert information about hurricane risk and potential impact into a neighborhood scale visualization of hurricane damage intended to improve public understanding and responsiveness. In the process, critical insights have been gained as to how to translate forecast information from text and photos into geographically precise visualizations that provide a local context to the audience. The context provided in the Hurricane Damage Visualization represents vital visual information to assist the public in pursuing an informed and wise course of action in anticipation of such a storm event. This visual and local context can deepen the meaning of weather impact communications and potentially persuade individuals to evacuate or take other measures to protect their lives and livelihoods. As our ability to predict the path and intensity of hurricanes increases, so too should our ability to effectively inform the perception of risk in the general public whose response is paramount to avoiding humanitarian disaster. The risk perception and awareness approaches and solutions raised by this Hurricane Damage Visualization could help prevent an extreme weather event from becoming a weather disaster. 


\section{References}

2015 Hurricane season, communicating hazards better [Motion picture]. (2015). USA: WUSA.

Burch, Sarah, Stephen RJ Sheppard, Alison Shaw, and David Flanders. "Planning for climate change in a flood-prone community: municipal barriers to policy action and the use of visualizations as decision-support tools." Journal of Flood Risk Management 3, no. 2 (2010): 126139.

Broad, Kenneth, Anthony Leiserowitz, Jessica Weinkle, and Marissa Steketee.

"Misinterpretations of the "cone of uncertainty" in Florida during the 2004 hurricane season." Bulletin of the American Meteorological Society 88, no. 5 (2007): 651-667.

Crampton, Jeremy W. "Maps as social constructions: power, communication and visualization." Progress in Human Geography 25, no. 2 (2001): 235-252.

Cutter, Susan, Bryan J. Boruff, and W. Lynn Shirley. "Social Vulnerability to Environmental Hazards." Hazards, Vulnerability, and Environmental Justice (2006): 115-132.

Demuth, Julie L., Eve Gruntfest, Rebecca E. Morss, Sheldon Drobot, and Jeffrey K. Lazo. "WAS*IS Building a Community for Integrating Meteorology and Social Science." Bulletin of the American Meteorological Society 88, no. 11 (2007): 1729-1737.

Demuth, Julie L., Jeffrey K. Lazo, and Betty Hearn Morrow. "Weather forecast uncertainty information: An exploratory study with broadcast meteorologists." Bulletin of the American Meteorological Society 90, no. 11 (2009): 1614-1618.

Demuth, Julie L., Rebecca E. Morss, Betty Hearn Morrow, and Jeffrey K. Lazo. "Creation and communication of hurricane risk information." Bulletin of the American Meteorological Society 93, no. 8 (2012): 1133-1145.

Esri R \& D Center Zurich.CityEngine Help Manual. Esri, Inc. Accessed: 29 March, 2017. http://cehelp.esri.com/help/index.jsp?topic=/com.procedural.cityengine.help/html/manual/cga /basics/toc.html

Franklin, James L., Michael L. Black, and Krystal Valde. "Eyewall Wind Profiles in Hurricanes Determined by GPS Dropwindsondes." National Hurricane Center, Retrieved February 1, 2017, from http://www.nhc.noaa.gov/aboutwindprofile.shtml

Gladwin, Hugh, Hugh E. Willoughby, Jeffrey K. Lazo, Betty Hearn Morrow, and Walter Gillis Peacock. "Social science research needs for the hurricane forecast and warning system." Bulletin of the American Meteorological Society 90, no. 1 (2009): 25-29. 
Goodchild, Michael F. "Geographic information systems." Progress in Human geography 15, no. 2 (1991): 194-200.

Google Search Result. "What is a category 1 hurricane?" 30 March, 2017. URL:

https://www.google.com/search?q=what+is+a+category+1+hurricane\&rlz=1C1GGGE enUS729U

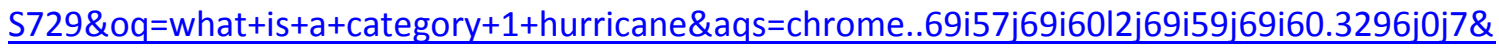
sourceid=chrome\&ie $=$ UTF-8

Guston, David H. "Boundary organizations in environmental policy and science: an introduction." Science, technology, and human values (2001): 399-408.

Jannuzzi et al. (2010). Service Assessment Southeast United States Floods, September 18-23, 2009. US Department of Commerce, 1-35. Retrieved April 11, 2015, from http://www.nws.noaa.gov/om/assessments/pdfs/se floods10.pdf

Lin, Ning, Kerry A. Emanuel, J. A. Smith, and E. Vanmarcke. "Risk assessment of hurricane storm surge for New York City." Journal of Geophysical Research: Atmospheres 115, no. D18 (2010).

Morrow, Betty H. "Risk behavior and risk communication: Synthesis and expert interviews." Final report for the NOAA coastal services center 53 (2009).

Morss, Rebecca E., Julie L. Demuth, Jeffrey K. Lazo. "Communicating Uncertainty in Weather Forecast: A Survey of the U.S. Public" Weather and Forecasting." (2008): 974-991.

Müller, Pascal, Peter Wonka, Simon Haegler, Andreas Ulmer, and Luc Van Gool. "Procedural modeling of buildings." In Acm Transactions On Graphics (2006), vol. 25, no. 3, pp. 614-623.

National Weather Service Weather Forecast Office (March 25, 2015 Severe Weather) http://www.srh.noaa.gov/tsa/?n=weather-event_2015mar25

Nicholson-Cole, Sophie A. "Representing climate change futures: a critique on the use of images for visual communication." Computers, environment and urban systems 29, no. 3 (2005): 255273.

NOAA's Weather-Ready Nation (NOAA's Weather-Ready Nation) http://www.nws.noaa.gov/com/weatherreadynation/

Parish, Yoav IH, and Pascal Müller. "Procedural modeling of cities." In Proceedings of the 28th annual conference on Computer graphics and interactive techniques. ACM, (2001): 301-308. 
Peacock, Walter Gillis, Samuel David Brody, and Wes Highfield. "Hurricane risk perceptions among Florida's single family homeowners." Landscape and Urban Planning 73, no. 2 (2005): 120-135.

Pennesi, Karen. "Improving Forecast Communication: Linguistic and Cultural Considerations." Journals of the American Meteorological Society July (2007): 1033-1044.

Pielke Jr, Roger A., Joel Gratz, Christopher W. Landsea, Douglas Collins, Mark A. Saunders, and Rade Musulin. "Normalized hurricane damage in the United States: 1900-2005." Natural Hazards Review (2008).

Rouleau, Tracy L. (2016). Risk Communication and Behavior Best Practices and Research Findings. July 2016. National Oceanic and Atmospheric Administration, 1-66. Accessed February 05, 2017. Retrieved February 5, 2017, from http://www.performance.noaa.gov/wpcontent/uploads/Risk-Communication-and-Behavior-Best-Practices-and-Research-Findings-July2016.pdf

"Saffir-Simpson Hurricane Wind Scale." National Hurricane Center. May 24, 2013. Accessed September 28, 2015. http://www.nhc.noaa.gov/aboutsshws.php. Schwarz, Michael, and Pascal Müller. "Advanced procedural modeling of architecture." ACM Transactions on Graphics (TOG) 34, no. 4 (2015): 107.

Sheppard, Stephen RJ. "Landscape visualisation and climate change: the potential for influencing perceptions and behaviour." Environmental Science \& Policy 8, no. 6 (2005): 637-654.

Sheppard, S. R., Shaw, A., Flanders, D., Burch, S., Wiek, A., Carmichael, J., \& Cohen, S. (2011). Future visioning of local climate change: a framework for community engagement and planning with scenarios and visualisation. Futures, 43(4), 400-412.

"Simple Procedural Destruction." Environmental Systems Research Institute. August 16, 2011. Accessed September 29, 2015. http://forums.esri.com/CityEngine/forum-17845.html.

Star, Susan Leigh, and James R. Griesemer. "Institutional ecology, translations' and boundary objects: Amateurs and professionals in Berkeley's Museum of Vertebrate Zoology, 190739." Social studies of science 19, no. 3 (1989): 387-420.

Sullivan, K. (2013). Service Assessment Hurricane/Post-tropical Cyclone Sandy, Oct. 22-29, 2012. US Department of Commerce, 1-66. Retrieved January 1, 2015, from http://www.nws.noaa.gov/os/assessments/pdfs/Sandy13.pdf 
Tucker, Catherine M., Hallie Eakin, and Edwin J. Castellanos. Perceptions of risk and adaptation: Coffee producers, market shocks, and extreme weather in Central America and Mexico. Global Environmental Change 20, no. 1 (2010): 23-32. doi:10.1016/j.gloenvcha.2009.07.006.

Vallee et al. (2013). Service Assessment The Record Front Range and Eastern Colorado Floods of September 11-17, 2013. US Department of Commerce, 1-49. Retrieved April 10, 2015, from http://www.nws.noaa.gov/om/assessments/pdfs/14colorado_floods.pdf

"NCAR - Weather and Society * Integrated Studies." NCAR - Weather and Society * Integrated Studies. Accessed February 27. 2017. http://www.sip.ucar.edu/wasis/.

National Weather Service, Weather Prediction Center Overview.

http://www.wpc.ncep.noaa.gov/\#page=ovw. Accessed February 28, 2017.

White, Dave D., Amber Wutich, Kelli L. Larson, Patricia Gober, Timothy Lant, and Clea Senneville. "Credibility, salience, and legitimacy of boundary objects: water managers' assessment of a simulation model in an immersive decision theater." Science and Public Policy 37, no. 3 (2010): 219. 


\section{Appendix I}

\section{CGA code}

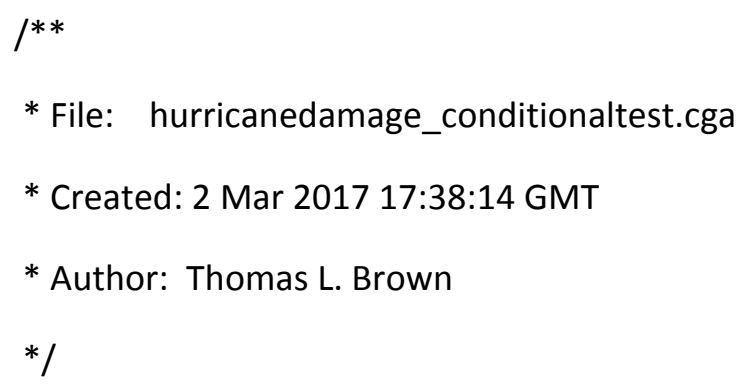


25\% : "assets/Walls/whiteSiding.tif"

$30 \%$ :"assets/Walls/graySiding.tif"

25\% : "assets/Walls/brick1.tif"

5\% : "assets/Walls/brick2.tif"

3\% : "assets/Walls/blueSiding.tif"

else : "assets/roofs/plywood.jpg"

attr resRoofColor $=$

15\% : "assets/roofs/roofSienna.tif"

5\% : "assets/roofs/roofGray.tif"

$20 \%$ : "assets/roofs/roofWhite.tif"

else : "assets/roofs/shingles01.jpg"

attr damagedroof $=$

45\% : "assets/roofs/roofSienna.tif"

15\% : "assets/roofs/roofWhite.tif"

else :"assets/roofs/plywood.jpg"

\#reflexive damage value used to determine building geometry changes from hurricane damage

@Group("Damage") @Range(0,8)

attr offset_damage $\quad=0$

\#end attribute catalog

@StartRule

Lot -->

cleanupGeometry(all, 0.97)

reduceGeometry (0.95)

alignScopeToGeometry (zUp, any, world.lowest) 
extrude (Height-.45*offset_damage)

comp(f) \{top: resRoof | side: resFacade | bottom: resFloor \}

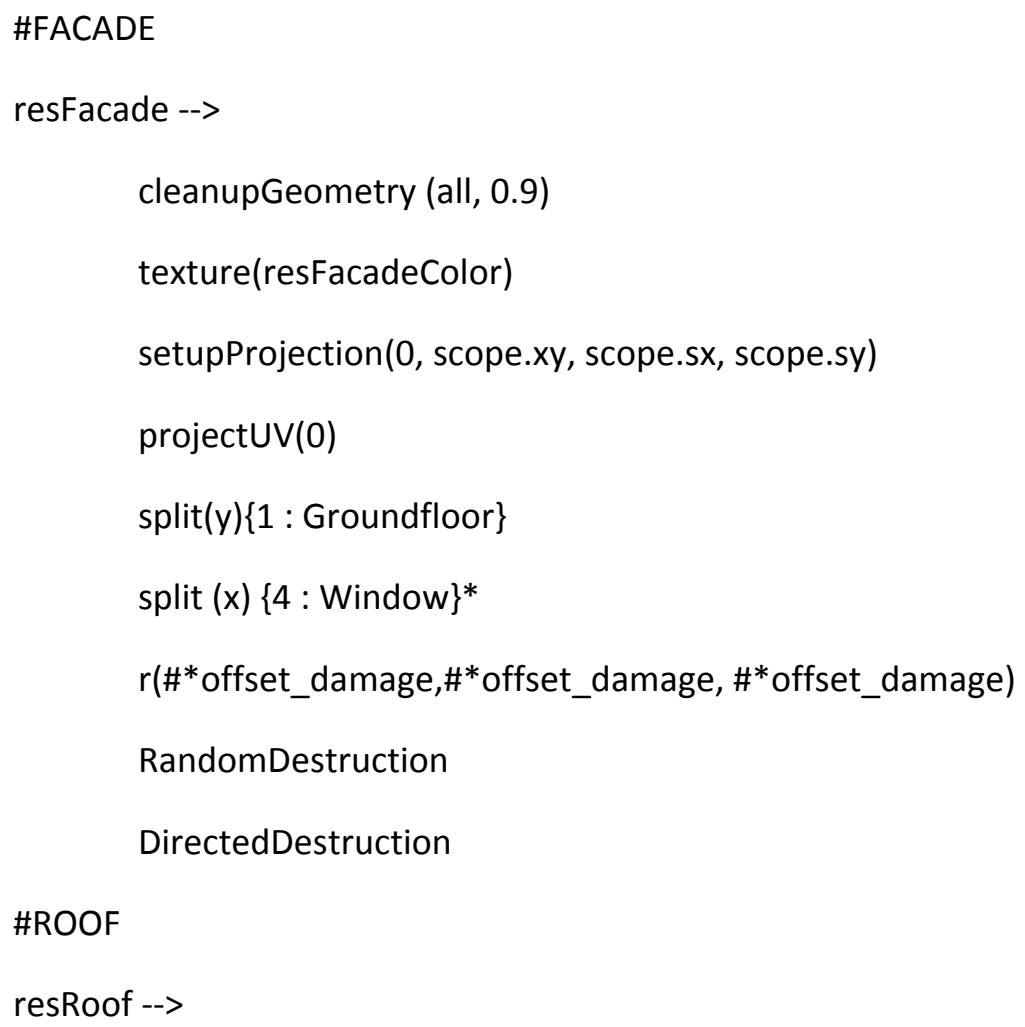


scaleUV $(0.2,6,3)$

texture (resRoofColor)

else:

cleanupGeometry (all, 0.9)

roofGable $(30,1)$

setupProjection(0, scope.xy, scope.sx, scope.sy)

texture(damagedroof)

projectUV(0)

scaleUV $(0.2,4,1.8)$

r(\#*offset_damage,\#*offset_damage, \#* offset_damage)

resFloor -->

cleanupGeometry (all, 0.9)

alignScopeToGeometry(zUp, world.lowest, scope.elevation)

setupProjection(0, scope.xy, scope.sx, scope.sy)

texture(resFacadeColor)

projectUV (0)

Treedebris

attr directedAngle $=\left(\#^{*}\right.$ offset_damage $)$

RandomDestruction -->

//fall down rotated

//builds conditional - no destruction happens when damage is 0

//when damage is greater than 0 the following geometric

//manipulations are applied

case offset_damage $==0$ :

i("models/model/model/palmtree.obj", yUp)

case offset_damage $==1$ : 


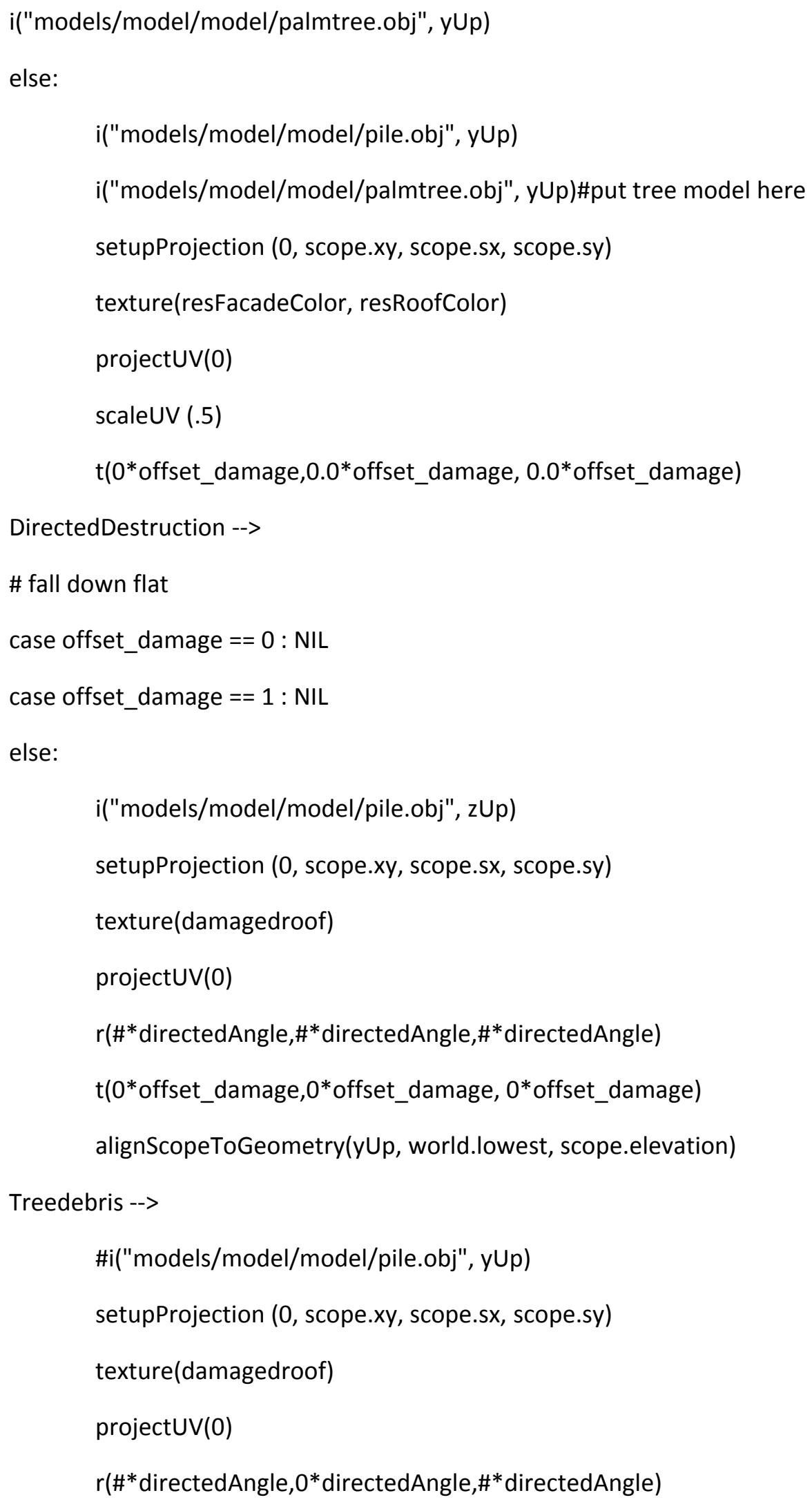


t(0*offset_damage,0*offset_damage, $0 *$ offset_damage)

alignScopeToGeometry(yUp, world.lowest, scope.elevation)

import id : "flood.cga"

//multiple attempts at visual parameterization

\#ScatterDebris

\#trim()

\#Debris

\#Destruction

\#rotate(rel, object, \#*offset_damage, \#*offset_damage)

\#translate (rel, object, 0, \#* offset_damage, \#*offset_damage)

\#trim()

\#split (y) \{tile :resFacade | offset_damage : Debris\}

\#split (x) \{tile : resFacade | offset_damage : alignScopeToAxes (x) Debris\}

\#split(y) \{tile: resFacade | offset_damage : alignScopeToAxes(y) Debris \}

\#split(u, uvSpace, 0) $\{3: X \mid$ offset_damage : Debris $\}$

\#FloodLayer -->

\#\#\#Moves the Debris along the surface of the building

\#\#\#or under whichever rule ScatterDebris is placed 


\section{Appendix II}

\section{Tables and Figures}

\section{Chapter 1}

Figure 1.1 "Hurricane Sandy Threat Index." Weather Channel. https://weather.com/storms/hurricane/news/hurricane-matthew-bahamasflorida-georgia-carolinas-forecast Accessed September 28, 2015.

Figure 1.2 "WPC surface analysis valid for 10/20/2012 at 03 UTC." Weather Prediction Center, National Weather Service. http://www.nhc.noaa.gov/graphics_at4.shtml?gm_track\#contents, Accessed February 28, 2017.

\section{Chapter 2}

Figure $2.1 \quad$ http://www.wfuv.org/content/timeline-sandy-aftermath

Figure 2.2 The Weather Channel. Access URL: http://static2.businessinsider.com/image/5097ded8eab8eadf37000001480/weather-channel-hurricane-sandy.png

Figure 2.3 (Weather Prediction Center Surface Analysis Oct. 30, 2012)

\section{Chapter 3}

Figure 3.1 Author Screenshot from CityEngine 2016.1 Hurricane Damage Proof of Concept

Figure 3.2 http://www.climatecentral.org/blogs/wild-weather-a-new-normal-insurancecompanies-must-act-14937 
Figure 3.3 https://www.engineeringexpress.com/forensic-engineering/

Figure 3.4 http://www.nhc.noaa.gov/1992andrew.html

Figure $3.5 \quad$ https://goclarkinsurance.com/wpcontent/uploads/sites/21/2015/10/storm damage homeowners insurance.jpg

Figure 3.6 Author Screen capture: CityEngine 2016.1

Figure 3.7 Author Screen capture: CityEngine 2016.1

Figure 3.8 Author Screen capture: CityEngine 2016.1

Figure 3.9 Author Screen capture: CityEngine 2016.1

Figure 3.10 Author Screen capture: SketchUp 2017

Figure 3.11 Author Screen capture: CityEngine 2016.1

\section{Chapter 4}

Figure $4.1 \quad$ (Parish and Muller 2001, 302)

Figure 4.2 Author Screen Capture CGA code: CityEngine 2016.1

Figure 4.3

http://cehelp.esri.com/help/index.jsp?topic=/com.procedural.cityengine.help/html/cgareferenc e/attr_scope.html

Figure 4.4 Author Screen Capture CGA code: CityEngine 2016.1

Figure 4.5 Author Screen Capture CGA code: CityEngine 2016.1

Figure 4.6 Author Screen Capture: CityEngine 2016.1

Figure 4.7 Author Screen Capture: CityEngine 2016.1

Figure 4.8 Author Screen Capture: CityEngine 2016.1

Figure 4.9 Author Screen Capture: CityEngine 2016.1

Figure 4.10 https://geonet.esri.com/externallink.jspa?url=http\%3A\%2F\%2Fforums.esri.com\%2FCityEngine\%2Fforum-17845.html

Figure 4.11 https://geonet.esri.com/externallink.jspa?url=http\%3A\%2F\%2Fforums.esri.com\%2FCityEngine\%2Fforum-17845.html

\section{Chapter 5}

Figure 5.1 Author Screen Capture : April 2017 


\section{Appendix III}

\section{Computer Specifications:}

GeForce Gigabyte 1080 Graphics Card 2.7-3.4 GHz

$512 \mathrm{~GB} 2.4 \mathrm{GHz}$ hard drive

Intel core i5 processor

16 GB DDR5 RAM

\section{Appendix IV}

\section{Evaluation discussion and Survey}

Please rank below how well each type of communication product about a potential hurricane impacting your area informed you about the potential risk and impact:

1 - least informative 5- most informative

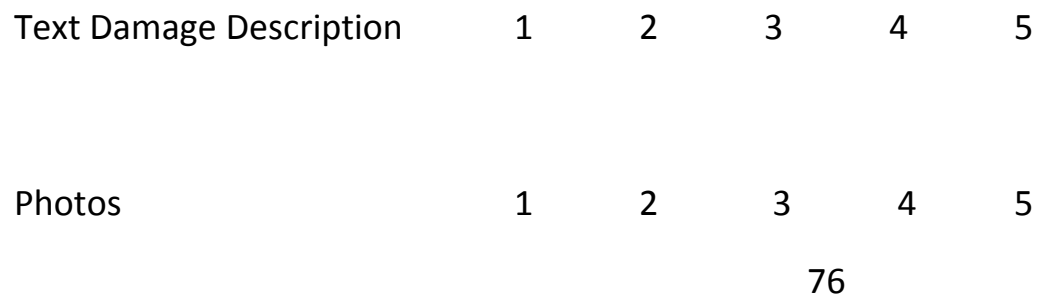


Hurricane Track Map

Satellite Hurricane Photo

3D Visualization
1

2

1

2

2

3

4

5

2

3

4

5

Did certain types of communication products have higher impact than others? Can you explain why?

Powerpoint slides used: 


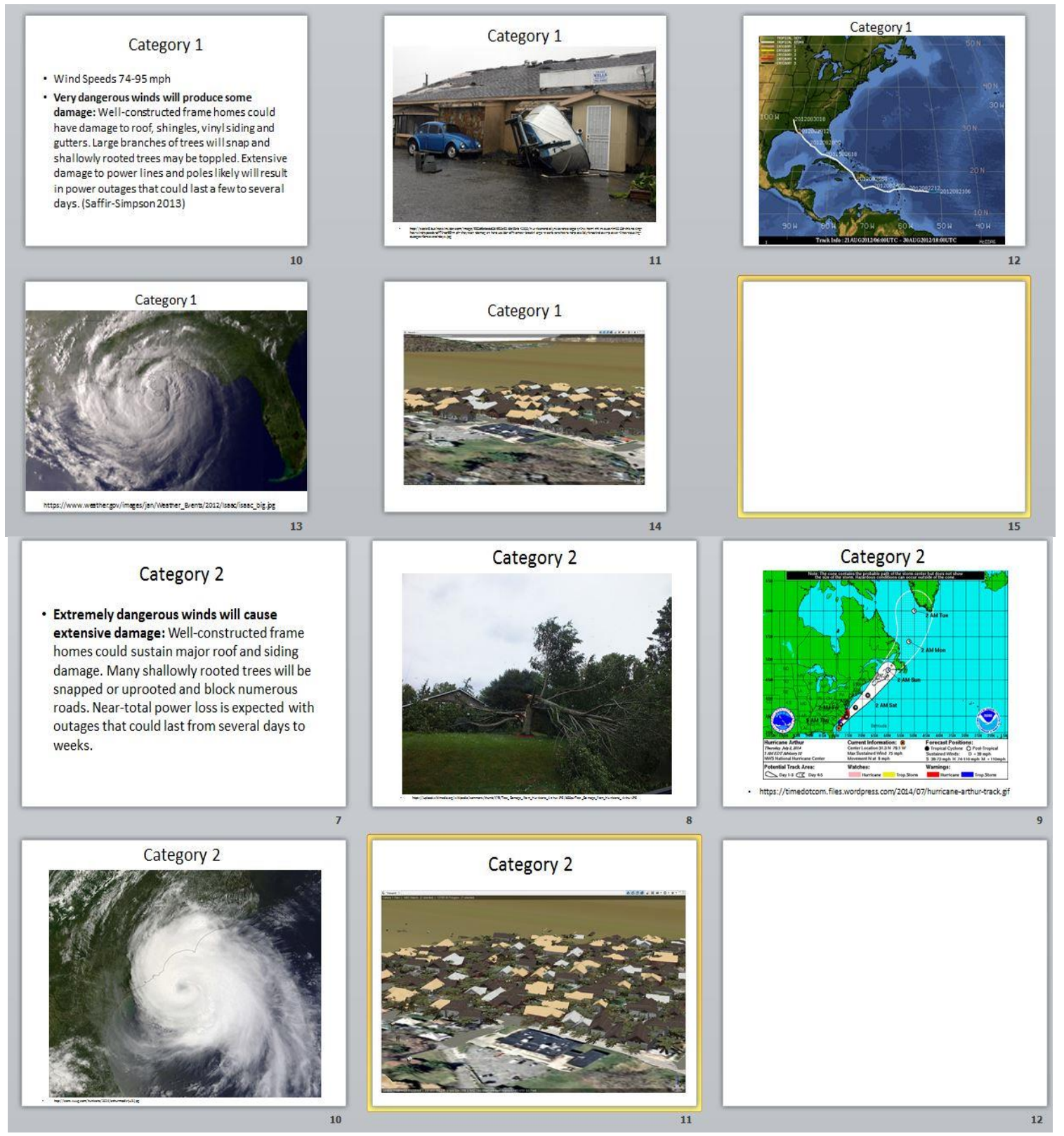




\section{Category 3}

- Devastating damage will occur: Well-built framed homes may incur major damage or removal of roof decking and gable ends. Many

trees will be snapped or uprooted, blocking numerous roads. Electricity and water will be unavailable for several days to weeks after the storm passes.

13

16

\section{Category 4}

- Catastrophic damage will occur: Well-built framed homes can sustain severe damage with loss of most of the roof structure and/or with loss of most of the roof structure and/c some exterior walls. Most trees will be
snapped or uprooted and power poles

snapped or uprooted and power poles
downed. Fallen trees and power poles will

isolate residential areas. Power outages will last weeks to possibly months. Most of the area will be uninhabitable for weeks or months.

19

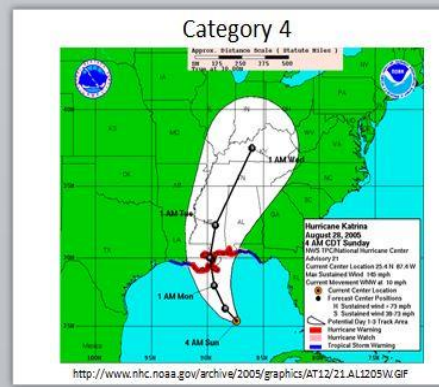

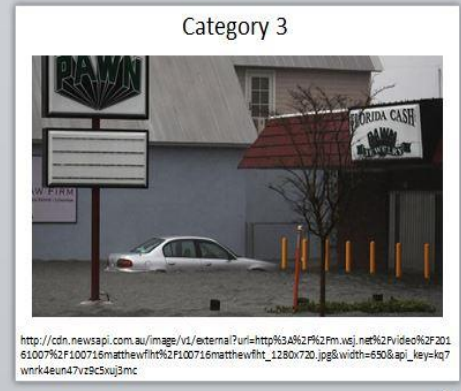
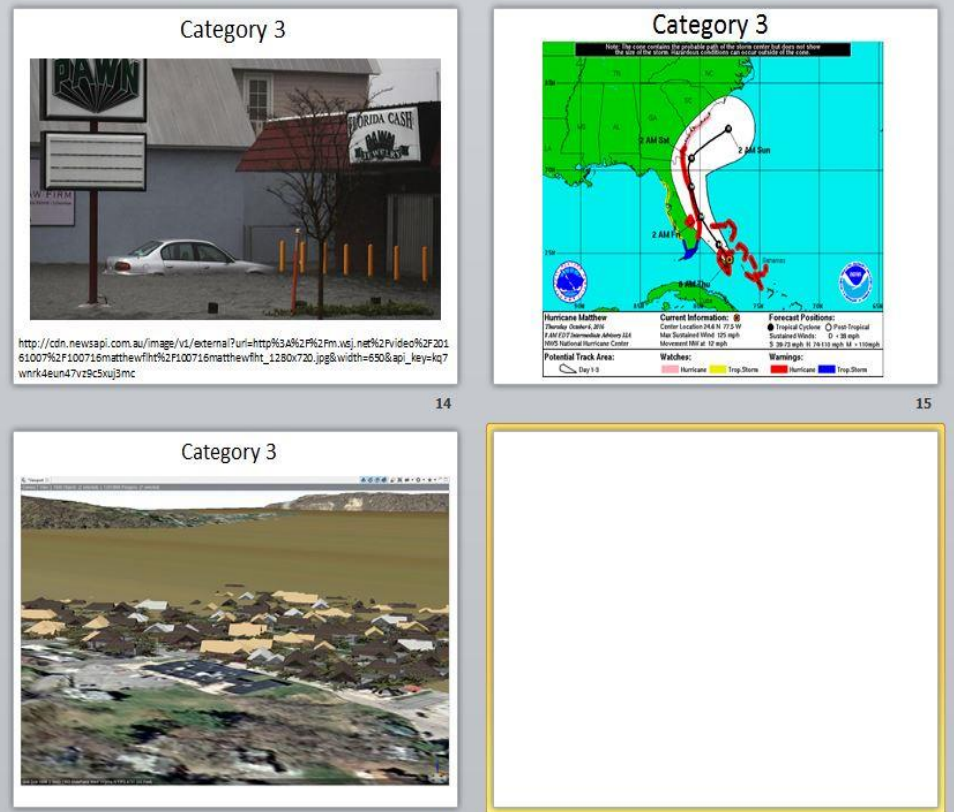

15
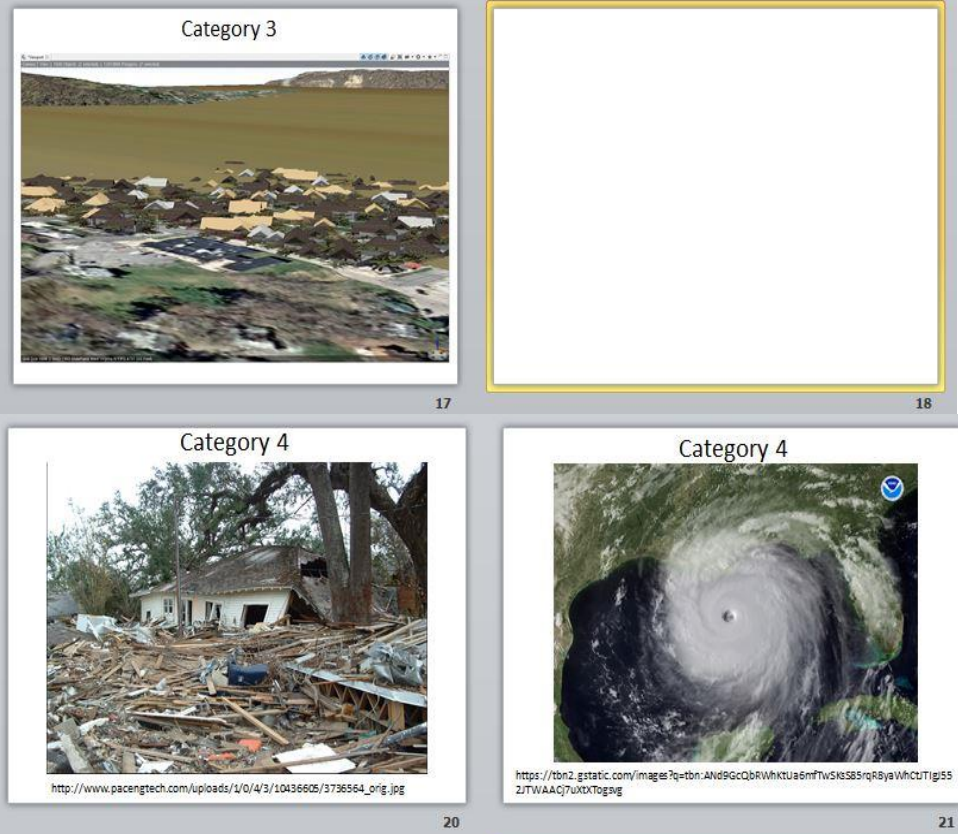

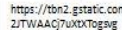

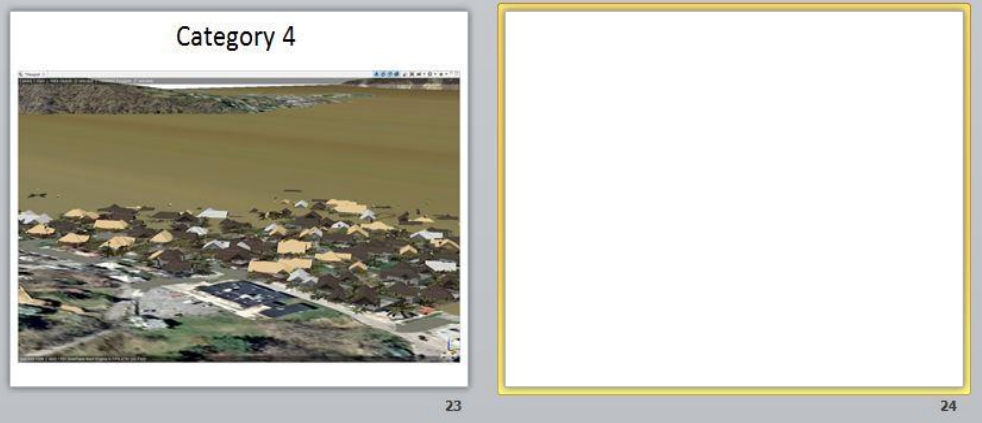




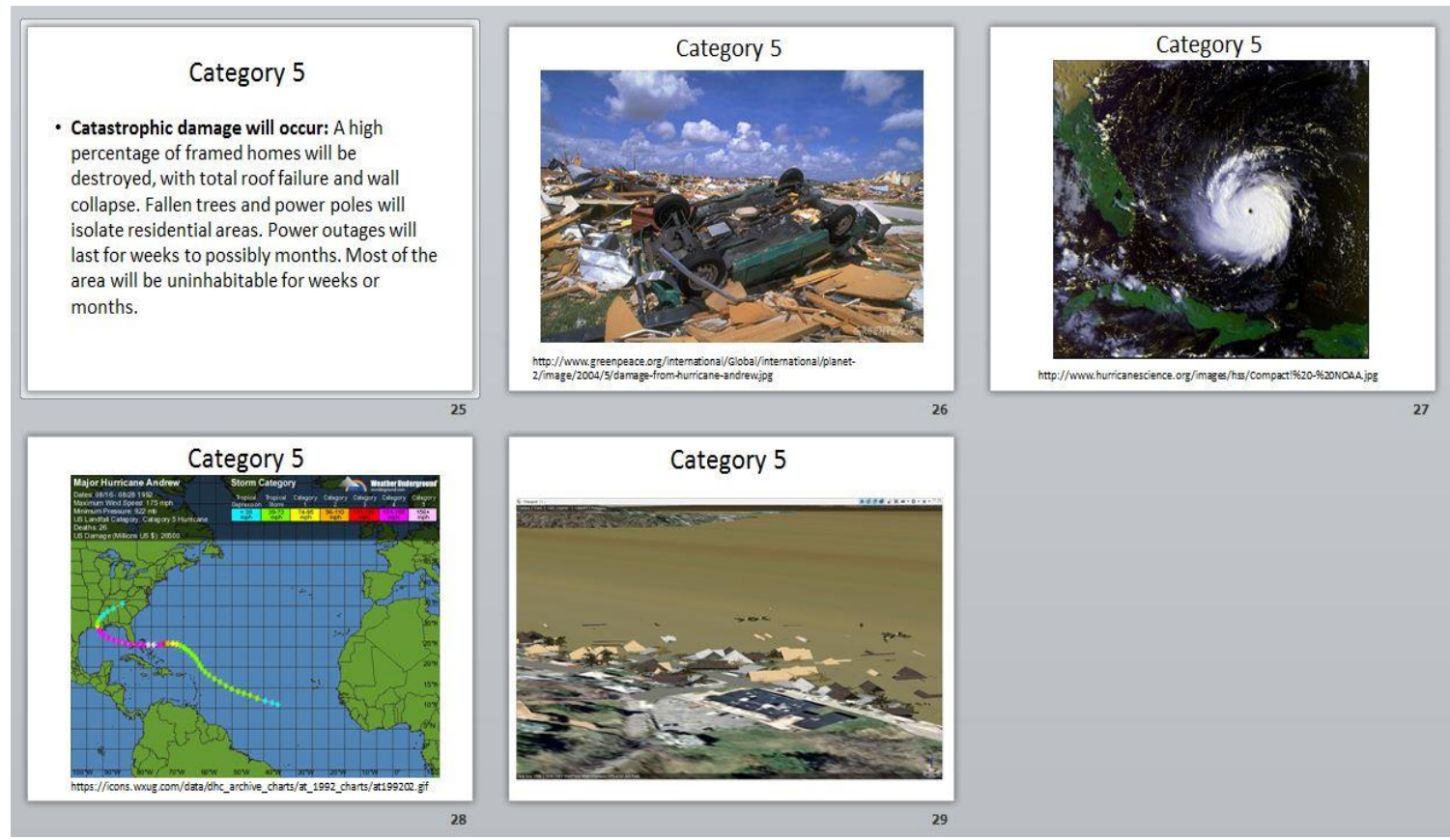

